\title{
Sulfur Doping versus Hierarchical Pore Structure: The Dominating Effect on the Fe-N-C Site Density, Activity, and Selectivity in Oxygen Reduction Reaction Electrocatalysis
}

Giorgia Daniel, Marco Mazzucato, Riccardo Brandiele, Laura De Lazzari, Denis Badocco, Paolo Pastore, Tomasz Kosmala, Gaetano Granozzi, and Christian Durante*

Cite This: ACS Appl. Mater. Interfaces 2021, 13, 42693-42705

Read Online

ABSTRACT: Nitrogen doping has been always regarded as one of the major factors responsible for the increased catalytic activity of $\mathrm{Fe}-\mathrm{N}-\mathrm{C}$ catalysts in the oxygen reduction reaction, and recently, sulfur has emerged as a co-doping element capable of increasing the catalytic activity even more because of electronic effects, which modify the d-band center of the $\mathrm{Fe}-\mathrm{N}-\mathrm{C}$ catalysts or because of its capability to increase the $\mathrm{Fe}-$ $\mathrm{N}_{x}$ site density (SD). Herein, we investigate in detail the effect of sulfur doping of carbon support on the $\mathrm{Fe}-\mathrm{N}_{x}$ site formation and on the textural properties (micro- and mesopore surface area and volume) in the resulting $\mathrm{Fe}-\mathrm{N}-\mathrm{C}$ catalysts. The $\mathrm{Fe}-\mathrm{N}-\mathrm{C}$ catalysts were prepared from mesoporous carbon with tunable sulfur doping (0-16 wt \%), which was achieved by the modulation of the relative amount of sucrose/ dibenzothiophene precursors. The carbon with the highest sulfur content

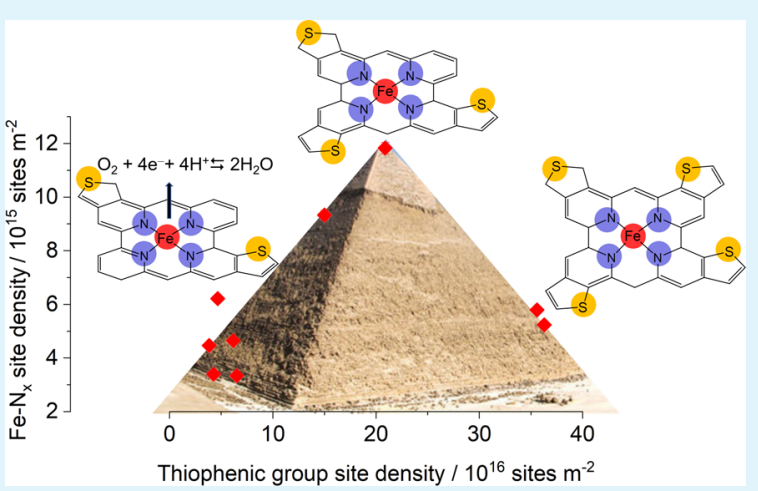
was also activated through steam treatment at $800{ }^{\circ} \mathrm{C}$ for different durations, which allowed us to modulate the carbon pore volume and surface area $\left(1296-1726 \mathrm{~m}^{2} \mathrm{~g}^{-1}\right)$. The resulting catalysts were tested in $\mathrm{O}_{2}$-saturated $0.5 \mathrm{M} \mathrm{H}_{2} \mathrm{SO}_{4}$ electrolyte, and the site density (SD) was determined using the NO-stripping technique. Here, we demonstrate that sulfur doping has a porogenic effect increasing the microporosity of the carbon support, and it also facilitates the nitrogen fixation on the carbon support as well as the formation of $\mathrm{Fe}-\mathrm{N}_{x}$ sites. It was found that the $\mathrm{Fe}-\mathrm{N}-\mathrm{C}$ catalytic activity $\left[E_{1 / 2}\right.$ ranges between 0.609 and $0.731 \mathrm{~V}$ vs reversible hydrogen electrode (RHE)] does not directly depend on sulfur content, but rather on the microporous surface and therefore any electronic effect appears not to be determinant as confirmed by X-ray photoemission spectroscopy (XPS). The graph reporting Fe$\mathrm{N}_{x}$ SD versus sulfur content assumes a volcano-like shape, where the maximum value is obtained for a sulfur/iron ratio close to 18, i.e., a too high or too low sulfur doping has a detrimental effect on $\mathrm{Fe}-\mathrm{N}_{x}$ formation. However, it was highlighted that the increase of $\mathrm{Fe}-\mathrm{N}_{x} \mathrm{SD}$ is a necessary but not sufficient condition for increasing the catalytic activity of the material, unless the textural properties are also optimized, i.e., there must be an optimized hierarchical porosity that facilitates the mass transport to the active sites.

KEYWORDS: PGM-free catalyst, ORR, $\mathrm{Fe}-\mathrm{N}-\mathrm{C}$, sulfur doping, hierarchical factor

\section{INTRODUCTION}

Fuel cell technologies represent an important development for moving to a low-carbon economy, which is expected to offer promising opportunities not only to fight climate change but also to enhance energy security, to revolutionize the transport sector, both for goods and people, and to develop local industries in many countries. ${ }^{1,2}$ Proof of this can be seen in the enormous investments in Europe and in the United States for the development of hydrogen-based technologies, including fuel cells (FC). ${ }^{3-6}$ In fact, even if the large majority of cars still employ fossil fuels, and battery-based electric vehicles are much more diffuse with respect to hybrid hydrogen cars, the FC technology is expected to play a pivotal role in the future for domestic decentralized energy production or in electric vehicles (FCEVs). With further technological improvement,
FCEVs will offer very fast refueling time (ca. 3-5 min), greater longevity, better driver experience and safety, and lower cost compared to the actual. Despite the economic and technological problems related to the production, transport, and storage of hydrogen, the main FCs problem is on a different aspect: the high cost due to the low kinetic of the cathode reaction, the oxygen reduction reaction (ORR), and thus, the usage of Pt-based materials as catalysts is still

Received: May 25, 2021

Accepted: July 30, 2021

Published: September 1, 2021 
required. ${ }^{7-9}$ With their low cost, high availability, and good tolerance to poisoning, non-precious-metal catalysts (nonPGM) are the best known alternative to $\mathrm{Pt}^{10-12}$ During past decades, various non-PGM catalysts were investigated: $\mathrm{M}-\mathrm{N}-$ $\mathrm{C}$ based on $\mathrm{M}-\mathrm{N}_{x}$ sites, non-precious-metal oxide, chalcogenides, and oxynitrides. ${ }^{13}$ The most studied are $\mathrm{M}-\mathrm{N}-\mathrm{C}$, and among them, the most active metal center is $\mathrm{Fe}$, where iron coordinate from two to five nitrogen functional groups, ${ }^{14}$ and among the different types of $\mathrm{Fe}-\mathrm{N}_{x}(x=1-5)$, the metal porphyrin-like $\mathrm{Fe}-\mathrm{N}_{4}$ site is considered the most important for its ORR selectivity and activity. ${ }^{15-18}$ However, different factors need to be considered to reach good performances, including site density, carbon support hierarchical structure, surface chemistry, graphitization degree, etc. ${ }^{19-25}$ Choosing the right carbon matrix is the turning point to improve catalytic performance; in fact, the increment of the active SD is per se not enough to enhance the activity, but it is necessary to rationally design the textural and porous properties of the carbon matrix to facilitate the mass transport between micropores and the bulk solution. ${ }^{23,26,27}$ Moreover, it has been also demonstrated that the incorporation of heteroatoms can influence the catalytic performances. ${ }^{28}$ The idea underlying the doping process is the capability of heteroatoms to modulate the electronic structure of the carbon plane via the delocalization of the $\pi$-electrons when pinned into the carbon framework, improving the catalyst activity. ${ }^{29}$ Several studies report that the doping of $\mathrm{N}$ atoms improves the ORR activity, which is mainly due to the pyridinic functional group. ${ }^{30}$ In fact, its presence encourages the adsorption of oxygen on the adjacent $\mathrm{C}$ atom. ${ }^{31}$ Besides $\mathrm{N}$ doping, other heteroatoms (e.g., $\mathrm{S}, \mathrm{P}$, and $\mathrm{B}$ ) can be embedded into $\mathrm{N}$-doped carbon structure generating synergistic effects between the dopants. Considering the $\mathrm{S}$ doping, the high electron spin density of doped $S$ atoms enhances the electrocatalytic activity, in particular the asymmetric charge density distribution creates adsorption sites enhancing the performance for the ORR. ${ }^{32-34}$ Another recent study demonstrates that $S$ doping activates carbon atoms next to graphitic $\mathrm{N}$ becoming ORR active sites. ${ }^{35}$ However, it is uncharted how the $S$ dopants interact with both Fe-based active sites and $\mathrm{N}$ species. The ORR activity of a single $\mathrm{Fe}-\mathrm{N}_{x}$ catalytic site seems to be biased by the introduction of electron-withdrawing/-donating groups, so only oxidized S functionality $\left(-\mathrm{SO}_{x}\right)$ should induce an increase of the ORR. ${ }^{36}$ However, it has been demonstrated that the main incorporated $\mathrm{S}$ structure is thiophene-like $(\mathrm{C}-\mathrm{S}-\mathrm{C})$ and that its beneficial effect in the ORR was observed to be dependent on the distance between the iron center and the $\mathrm{S}$ atom. ${ }^{37}$

The aim of this paper is to understand whether $S$ doping can indeed produce measurable improvements in the formation of $\mathrm{Fe}-\mathrm{N}_{x}$ active sites, in the catalytic activity and selectivity of the resulting material, and whether this effect prevails on other material properties such as the hierarchical pore structure or the graphitization degree, ${ }^{38}$ or even if the improvement is due to indirect effect of sulfur on other properties of materials. To do so, here, we employed S-doped mesoporous carbon (SMC) prepared by hard template approach ${ }^{8,39}$ and iron phenanthroline that was used as $\mathrm{N}$ and Fe precursor for the formation of Fe-N-C sites. $^{10,24}$

\section{EXPERIMENTAL SECTION}

2.1. Synthesis of the Carbon Supports. Sucrose and dibenzothiophene (DBT) were used as carbon and sulfur precursors, respectively, for the synthesis of different SMCs. Differently doped
SMCs were prepared by changing the ratio between the two precursors, and the corresponding mesoporous carbon (MC) have been labeled as SMC (only dibenzothiophene), SMC70 (70:30, dibenzothiophene/sucrose), SMC50, SMC30, and MC (only sucrose). For all of the supports, the preparative procedure consists of the dissolution of $1 \mathrm{~g}$ of silica ( $200 \mathrm{~nm}$ particle size, $4 \mathrm{~nm}$ pore size, from Sigma-Aldrich) and $1 \mathrm{~g}$ of organic precursor in $15 \mathrm{~mL}$ of acetone or ethanol depending on the precursor solubility in the medium. $\mathrm{H}_{2} \mathrm{SO}_{4}(200-300 \mu \mathrm{L})$ was also added to facilitate the oligomerization of the precursors during the impregnation process. ${ }^{28}$ Silica acts as a template matrix, imprinting the mesoporosity to the resulting MCs. The solution was dried in an oven for over $1 \mathrm{~h}$ at $100{ }^{\circ} \mathrm{C}$, to remove all traces of solvent until a brownish powder remains. The powder was then treated in a tubular furnace applying a ramp of $5{ }^{\circ} \mathrm{C} \mathrm{min}^{-1}$ until the temperature reaches $750{ }^{\circ} \mathrm{C}$ under $\mathrm{N}_{2}$ flow. Once the temperature was reached, the compound was left in the tube for $2 \mathrm{~h}$ at a constant temperature. The system was then cooled down until room temperature was reached. The final step for the carbon powder consists of the etching of the template by treating it with liquid solution of $20 \mathrm{~mL}$ of $\mathrm{NaOH}$ and $20 \mathrm{~mL}$ of ethanol in a bath sonicator to ensure the removal of silica from MCs, which was confirmed by the absence of the Si $2 \mathrm{p}$ peak attributed to $\mathrm{SiO}_{2}$ around $103 \mathrm{eV}$ in the Xray photoemission spectroscopy (XPS) survey spectrum. The mixture reacts with the silica by dissolving it, while the carbon precipitates and is eventually separated by vacuum filtration on a nylon filter (GVC, nylon $0.2 \mu \mathrm{m}, 47$ membrane diameter). ${ }^{8}$

2.2. Steam Activation Treatment. The sole SMC sample was subjected to different steam activation treatments. The steam treatment consists of treating at high temperature the carbon powder in a tubular furnace, where the inlet flange lodges a stainless steel needle which tip is fixed at the entrance of the oven. ${ }^{23}$ This apparatus was connected to a syringe pump (SKE Research Equipment). Before performing the activation treatment, the tubular furnace was purged with $\mathrm{N}_{2}$, and then the temperature was increased up to $800{ }^{\circ} \mathrm{C}$, and when reached by means of a syringe pump, Milli- $Q$ water at $1 \mathrm{~mL}$ $\mathrm{min}^{-1}$ was injected with the almost instantaneous water evaporation. The steam atmosphere was maintained for different dwelling times: 5 , 20, 40, and $60 \mathrm{~min}$ obtaining the samples SMCSt5, SMCSt20, SMCSt40, and SMCSt60, respectively.

2.3. Synthesis of $\mathbf{F e}-\mathbf{N}-\mathrm{C}$ Materials. Iron(II)-phenanthroline chloride $\left(\mathrm{Fe}(\mathrm{Phen})_{3} \mathrm{Cl}_{2}\right)$ was synthesized from $\mathrm{FeCl}_{2}$ and 1,10phenanthroline monohydrate in ethanol according to literature. ${ }^{10}$ The synthesis of $\mathrm{Fe}-\mathrm{N}-\mathrm{C}$ catalysts was carried out as follow: $200 \mathrm{mg}$ of MCs (SMCX or SMCstX) and $222 \mathrm{mg}$ of $\mathrm{Fe}(\text { phen })_{3} \mathrm{Cl}_{2}$ (2\% molar of iron with respect to the molar amount of carbon) were mixed with a ball-miller (Retsch MM 400, $10 \mathrm{~mL}$, and $5 \mathrm{~mL}$ steel jars with steel balls) at $20 \mathrm{~Hz}$ for $20 \mathrm{~min}$, then heated at $900{ }^{\circ} \mathrm{C}$ in a tubular furnace (Carbolite, with a quartz tube $\emptyset=25 \mathrm{~mm}$ ) for $2 \mathrm{~h}$ under nitrogenhydrogen atmosphere $\left(8 \% \mathrm{H}_{2}\right.$ in the mixture), and cooled down to room temperature under pure nitrogen flow. The resulting powder was vibro-milled and leached at reflux at $100{ }^{\circ} \mathrm{C}$ in $100 \mathrm{~mL}$ of $1 \mathrm{M}$ $\mathrm{H}_{2} \mathrm{SO}_{4}$ for $3 \mathrm{~h}$ under continuous stirring. The solution was then filtered and washed with at least $500 \mathrm{~mL}$ of Milli-Q water using nylon membrane and finally dried in an oven at $80{ }^{\circ} \mathrm{C}$ overnight. After the acid washing, the Fe-based powder was heated a second time at 900 ${ }^{\circ} \mathrm{C}$ under $\mathrm{H}_{2} / \mathrm{N}_{2}$ flow as described before. The resulting powders are labeled: FeSMCX, FeMC, and FeSMCStW (where $X$ is the percentage of DBT and $\mathrm{W}$ is the dwelling time of steam). The final catalysts were ground for $30 \mathrm{~min}$ at $24 \mathrm{~Hz}$ before the characterizations.

2.4. Electrochemical Test. Cyclic voltammetry (CV) and linear sweep voltammetry (LSV) were carried out on a rotating ring-disk electrode (RRDE, Metrohm; $d=5 \mathrm{~mm}$ GC disk and a Pt ring), in both Ar-purged and $\mathrm{O}_{2}$-saturated $0.5 \mathrm{M} \mathrm{H}_{2} \mathrm{SO}_{4}$ solution using an Autolab model $101 \mathrm{~N}$ potentiostat. All measurements were done in a three-electrode cell thermostated at $25{ }^{\circ} \mathrm{C}$. The RRDE tip was used as the working electrode, a graphite rod was used as the counter electrode, and a homemade RHE as the reference electrode. ${ }^{40}$ RHE consists of a spiral Pt wire settled to the closed end of a capillary glass tube filled with the electrolyte solution in which $\mathrm{H}_{2}$ was directly 
Table 1. Bulk Composition Derive from Elemental Analysis and ICP-MS (Fe) Analysis

\begin{tabular}{|c|c|c|c|c|c|c|c|}
\hline & $\mathrm{C}_{\text {support }}{ }^{a}($ wt $\%)$ & $\mathrm{S}_{\text {support }}{ }^{a}($ wt $\%)$ & $\mathrm{C}_{\mathrm{cat}}{ }^{a}(\mathrm{wt} \%)$ & $\mathrm{H}_{\mathrm{cat}}{ }^{a}(\mathrm{wt} \%)$ & $\mathrm{N}_{\mathrm{cat}}{ }^{a}($ wt $\%)$ & $\mathrm{S}_{\mathrm{cat}}{ }^{a}(\mathrm{wt} \%)$ & $\mathrm{Fe}_{\mathrm{cat}}{ }^{b}(\mathrm{wt} \%)$ \\
\hline FeSMC & 75.18 & 16.71 & 78.37 & 1.20 & 1.81 & 2.35 & 0.40 \\
\hline FeSMC70 & 57.20 & 11.57 & 67.54 & 1.11 & 1.78 & 1.81 & 0.68 \\
\hline FeSMC50 & 75.82 & 10.29 & 82.47 & 0.66 & 1.48 & 0.94 & 0.80 \\
\hline FeSMC30 & 61.87 & 5.57 & 85.34 & 0.45 & 1.46 & 1.24 & 1.09 \\
\hline FeMC & 90.55 & $<1$ & 75.18 & 0.99 & 0.98 & 0.11 & 1.17 \\
\hline FeSMCSt5 & 78.44 & 11.64 & 79.41 & 1.17 & 1.06 & 0.48 & 0.25 \\
\hline FeSMCSt20 & 85.63 & 8.02 & 78.57 & 1.07 & 0.86 & 0.58 & 1.03 \\
\hline FeSMCSt40 & 68.40 & 3.36 & 76.07 & 1.28 & 1.41 & 0.31 & 1.03 \\
\hline FeSMCSt60 & 83.75 & 2.60 & 79.46 & 1.13 & 0.99 & 0.31 & 0.87 \\
\hline
\end{tabular}

electrogenerated at the Pt wire via the chronoamperometric technique until half of the spiral was filled with gas.

The material activity was investigated on a catalyst layer loaded on GC surface via drop-casting after the preparation of an ink made approximately of an 8:1:1 mixture of water, two organic solvents [chosen from ethanol, acetone, isopropanol, dimethylformamide (DMF), and tetrahydrofuran (THF) $]$, and Nafion $\left(m_{\text {nafion solution }} / m_{\text {cat }}\right.$ $\approx 0.8$ ). The dispersion of the powder was ensured using a bath sonicator at a controlled temperature. The loading was chosen to be $0.6 \mathrm{mg} \mathrm{cm}^{-2}$ as used in previous works. ${ }^{11,24}$

All of the materials were initially activated in Ar-purged electrolyte with extensive $\mathrm{CV}$ cycling at $200 \mathrm{mV} \mathrm{s}^{-1}$ until a stable current was observed. In ORR tests, $\mathrm{O}_{2}$ was bubbled inside the electrolyte solution for at least $30 \mathrm{~min}$. The number of transferred electron $(n)$ was determined by RRDE linear sweep voltammetry according to the following equation

$$
n=\frac{4\left|i_{D}\right|}{\left|i_{D}\right|+\left|i_{R}\right| / N}
$$

where $i_{\mathrm{D}}$ is the current recorded at disk, $i_{\mathrm{R}}$ is the current recorded at ring, and $N$ is the collection efficiency, which is equal to 0.25 (determined by performing RRDE measurement in the presence of $\mathrm{K}_{4} \mathrm{Fe}(\mathrm{CN})_{6}$ in $0.5 \mathrm{M} \mathrm{K}_{2} \mathrm{SO}_{4}$ electrolyte). With the last analysis, it is also possible to evaluate the percentage of hydrogen peroxide produced at the working electrode

$$
\chi_{\mathrm{H}_{2} \mathrm{O}_{2}} \%=100 \times \frac{4-n}{2}=\frac{100 \times 2\left|i_{\mathrm{R}}\right|}{N \times\left|i_{\mathrm{D}}\right|+\left|i_{\mathrm{R}}\right|}
$$

Other parameters of interest are the half-wave potential $\left(E_{1 / 2}\right)$, and the limiting current density $\left(j_{\mathrm{L}}\right)$ determined from LSV analysis at 1 $\mathrm{mV} \mathrm{s}^{-1}$ and $1600 \mathrm{rpm}$. The mass-transport-corrected kinetic current density $\left(j_{\mathrm{k}}\right)$ at a selected potential is calculated according to eq 3 .

$$
j_{\mathrm{k}}=\frac{j_{\mathrm{E}} \cdot j_{\mathrm{L}}}{j_{\mathrm{E}}-j_{\mathrm{L}}}
$$

where $j_{\mathrm{E}}$ is the current density at the selected potential $E=0.8 \mathrm{~V}$ vs RHE and $j_{\mathrm{L}}$ is the limiting current.

To evaluate the catalysts site density, nitrite $\left(\mathrm{NO}_{2}^{-}\right)$poisoning and electrochemical stripping were performed following the procedure described by Malko et al. ${ }^{41}$ This procedure takes advantage of the selective nitrite adsorption on $\mathrm{Fe}-\mathrm{N}_{x}$ site, in detail, allowing the calculation of the site density from the charge of NO reductive stripping during a $\mathrm{CV}$ measurement. The site density measurements were also performed on a thin layer of catalyst deposited on a GC (RDE, Metrohm $d=5.5 \mathrm{~mm}$ ) in a $0.5 \mathrm{M}$ acetate buffer at $\mathrm{pH} 5.2$; for that reason, the reference electrode was changed to a saturated calomel (SCE). A loading of $0.2 \mathrm{mg} \mathrm{cm}{ }^{-2}$ was chosen according to published procedure.

The nitrosyl stripping charge, $Q_{\text {strip}}$, can be related to the gravimetric site density according to the formula

$$
\operatorname{MSD}\left[\text { mol sites g }{ }^{-1}\right]=\frac{Q_{\text {strip }}\left[\mathrm{C} \mathrm{g}^{-1}\right]}{n_{\text {strip }} F\left[\mathrm{C} \mathrm{mol}^{-1}\right]}
$$

where $n_{\text {strip }}$ is the number of electrons associated with the reduction of one adsorbed nitrosyl per site to $\mathrm{NH}_{3}$ (or more precisely to $\mathrm{NH}_{4}^{+}$), which is equal to 5 . The turnover frequency (TOF) of $\mathrm{Fe}-\mathrm{N}_{x}$ sites is then given by the expression

$$
\text { TOF[electron sites } \left.{ }^{-1} \mathrm{~s}^{-1}\right]=\frac{j_{\mathrm{k}}\left[\mathrm{A} \mathrm{g}^{-1}\right]}{\mathrm{MSD}\left[\mathrm{mol} \mathrm{sites}^{-1}\right] \cdot F\left[\mathrm{C} \mathrm{mol}^{-1}\right]}
$$

where $F$ is the Faraday constant and $j_{\mathrm{k}}$ is the kinetic current (or mass activity) determined by the Tafel plot.

2.5. Physicochemical Characterization. X-ray photoemission spectroscopy (XPS) measurements were performed at room temperature in a UHV chamber (base pressure $<5 \times 10^{-9} \mathrm{mbar}$ ), equipped with a double-anode X-ray source (Omicron DAR-400) and a hemispherical electron analyzer (Omicron EIS-125). A nonmonochromatized $\mathrm{Mg} \mathrm{K} \alpha$ radiation $(h \nu=1253.6 \mathrm{eV})$ and pass energies of 50 and $20 \mathrm{eV}$ for the survey and the single spectral windows, respectively, were used. The calibration of the binding energy (BE) scale was carried out using $\mathrm{Au} 4 \mathrm{f}^{7 / 2}$ as a reference $\left(\mathrm{BE} A u 4 \mathrm{f}^{7 / 2}=84.0\right.$ $\mathrm{eV}$ ). The XPS peak of nitrogen was deconvoluted into single components using symmetrical Voigt functions.

Raman spectra were recorded using a micro-Raman setup with a $0.7 \mathrm{~mW}$ laser at $633 \mathrm{~nm}$ with $20 \times$ LWD objective (pinhole $25 \mu \mathrm{m}$ ). $\mathrm{N}_{2}$ adsorption/desorption isotherms were recorded at $77.3 \mathrm{~K}$ using an ASAP 2020 Plus instrument. Specific surface area of the samples was determined by the Brunauer-Emmett-Teller (BET) analysis and with the quenched-solid density functional theory (QSDFT) model. It takes into account the interconnectivity among pores, the interactions between adsorbent and adsorbate, and the roughness of porous surface. The total volume of pore was obtained applying Gurvitsch law at $p / p^{0} \approx 0.98$. Elemental analysis $(\mathrm{EA})$ was carried out using a Thermo Scientific Flash 2000 analyzer. Transmission electron microscopy (TEM) images were obtained with an FEI TECNAI G2 instrument operating at $100 \mathrm{kV}$.

An Agilent Technologies $7700 \times$ inductively coupled plasma-mass spectrometer (ICP-MS) was employed for inductively coupled plasma-mass spectrometry analysis. The samples $(10 \mathrm{mg})$ for ICP analysis were treated for $1 \mathrm{~h}$ at $100{ }^{\circ} \mathrm{C}$ using $2 \mathrm{~mL}$ of concentrated nitric acid immersed in a water bath.

\section{RESULTS AND DISCUSSION}

The S-doped supports were synthesized using a hard template approach; the reader may refer to the Experimental Section for details. The P200 is a commercial mesoporous silica composed of spherical particle of $200 \mathrm{~nm}$ in diameter, with inner pore size of $4 \mathrm{~nm}$ and a declared surface area of $823 \mathrm{~m}^{2} \mathrm{~g}^{-1}$. The hard template synthesis allows us to synthesize MC with superimposable morphology (same particle dimension and shape), while the chemical functionalization can be varied at will 
(a)

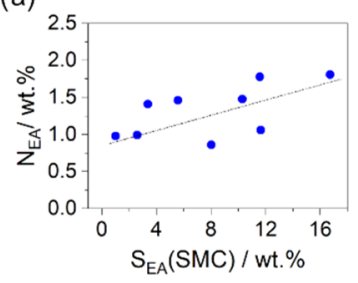

(b)

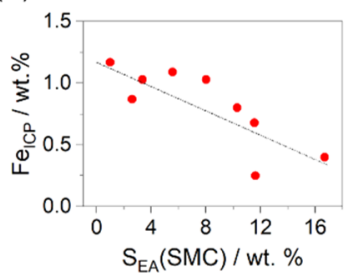

(c)

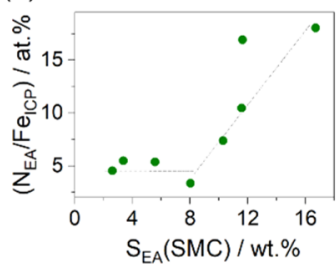

(d)

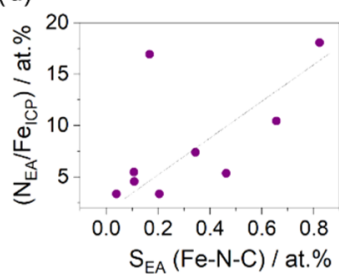

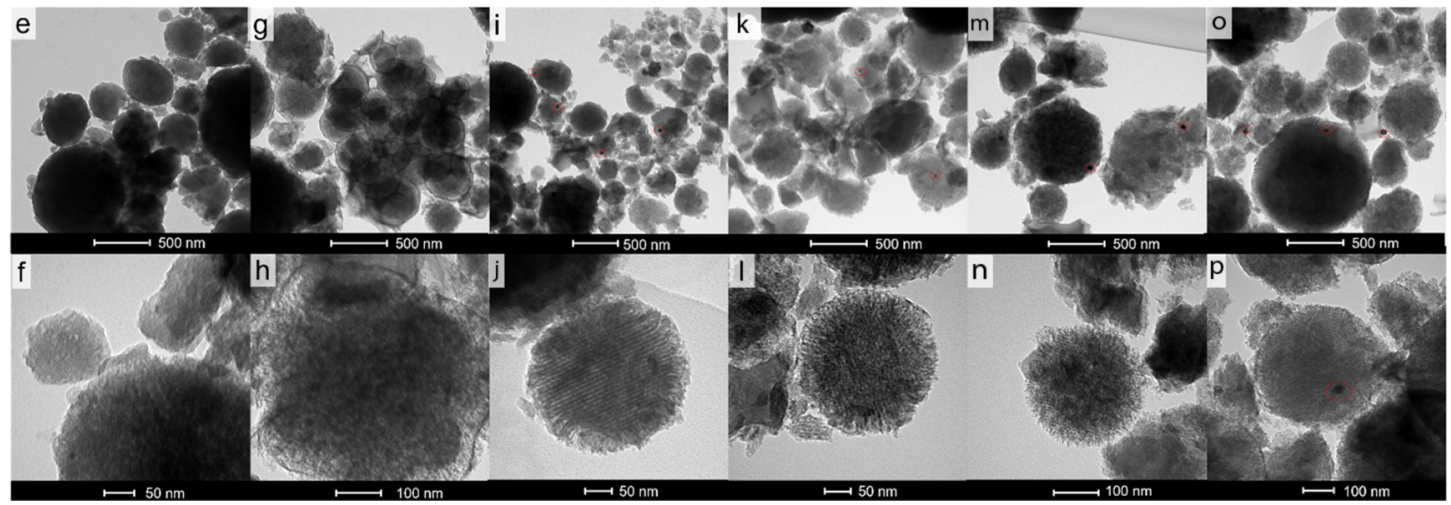

Figure 1. $(\mathrm{a}-\mathrm{d})$ Correlation of element quantity determined from EA or ICP-MS. SMC and $\mathrm{Fe}-\mathrm{N}-\mathrm{C}$ are meant to identify the carbon supports and the catalysts, respectively (dotted lines are only intended to guide the eye); (e-p) TEM images of (e, f) FeSMC, (g, h) FeMC, (i, j) FeSMCSt5, (k, 1) FeSMCSt20, (m, n) FeSMCSt40, and (o, p) FeSMCSt60. Red circles indicate the presence of iron NPs.

(different content of sulfur functional groups). The steam activation at $800{ }^{\circ} \mathrm{C}$ of SMC at different dwelling times in the oven chamber was also evaluated with the aim of understanding the effect of textural properties on $\mathrm{Fe}-\mathrm{N}_{x}$ sites formation. In fact, it is expected the steam treatment can improve the textural properties (pore surface area and volume) of the carbon supports and the relative content of graphitized carbon. The obtained carbon supports were employed for the preparation of $\mathrm{Fe}-\mathrm{N}-\mathrm{C}$ catalysts by the thermochemical reaction of a mixture of the modified carbon support and $\mathrm{Fe}(\mathrm{Phen})_{3} \mathrm{Cl}_{2}$. The thermal treatments can generate small etching molecules such as $\mathrm{SO}_{2}, \mathrm{CO}$, and $\mathrm{CO}_{2}$ that can induce a modification of the textural properties as previously observed also with other doped carbon supports. ${ }^{8,42}$ CHNS elemental analysis confirmed the successful doping of the SMC samples (Table 1), which have sulfur contents proportional to the dibenzothiophene/sucrose ratio employed in the synthesis. When $100 \%$ DBT was used, the sulfur percentage reaches $16.71 \%$, and it decreased to $11.57,10.29$, and $5.57 \%$ as the $\mathrm{DBT} /$ sucrose ratio is decreased to $70: 30,50: 50$, and 30:70, respectively. The sample prepared by the sole sucrose, as expected, does not show appreciable sulfur (Table 1, entry 5). The steam treatment performed on SMC has the effect to decrease the sulfur content and the residual sulfur is proportional to the treatment time, i.e., the more the sample is exposed to the action of the steam at high temperatures, the more the sulfur content decreases. In fact, the sulfur content decreases from 16.71 to $2.60 \%$ passing from 0 to $60 \mathrm{~min}$ of treatment (Table 1). This can be explained by the fact that the steam tends to react with the amorphous component of the sample and with graphitic grain boundaries, where the sulfur functional groups are located. ${ }^{43,44}$ In $\mathrm{Fe}-\mathrm{N}-\mathrm{C}$ catalysts sulfur functional groups are still present but in a different percentage with respect to the pristine carbon supports (Table 1). In fact, the percentage of sulfur remains proportional to the initial content, i.e., FeSMC shows the highest percentage (2.35\%) while the lowest percentage is observed in FeMC (0.11\%), and intermediate values are observed for $\mathrm{Fe}-\mathrm{N}-\mathrm{C}$ samples prepared from carbons with a decreasing ratio of dibenzothiophene to sucrose (Table 1). The set of $\mathrm{Fe}-\mathrm{N}-\mathrm{C}$ catalysts prepared from steam-activated SMC show even lower sulfur values in the range $0.6-0.3 \mathrm{wt} \%$. It is interesting to note that the nitrogen percentage in FeSMC samples shows a certain proportionality with the sulfur content initially present in the carbonaceous media, i.e., the nitrogen content is higher where the sulfur content was also initially higher (Figure 1a). Even if the data are scattered and a perfect linear correlation cannot be obtained, the trend is clear. An opposite trend can be observed for iron determined via ICP-MS (the Fe content spans between 0.25 and $1.17 \mathrm{wt} \%)$, i.e., the iron content remaining after heat treatments and acid washing scales inversely to the initial sulfur content (Figure 1b). Considering that there must be some proportionality between iron and nitrogen content, as the ORR active sites consist of a metal center capable of coordinating two to five nitrogen atoms, Figure 1c shows the $\mathrm{N} / \mathrm{Fe}$ ratio against the sulfur content in the carbonaceous support, expressed as atomic percentage. It is worth reminding that Fe contents estimated by ICP cannot represent the $\mathrm{Fe}-\mathrm{N}_{x}$ contents, but it gives an overestimation of $\mathrm{Fe}-\mathrm{N}_{x}$ sites, since the presence of iron nanoparticles (NPs) leads to the concomitant presence of iron oxides, although these remain inactive due to a carbonaceous coating that does not allow their dissolution during the acid treatment. ${ }^{11}$ However, the iron content not in the form $\mathrm{Fe}-\mathrm{N}_{x}$ can be treated as a systematic error and therefore even if not indicative of absolute value it, becomes so in relative value. What can be observed is that ideal $\mathrm{N} / \mathrm{Fe}$ ratio to form $\mathrm{Fe}-\mathrm{N}_{4}$ can be easily obtained even at a low sulfur percentage, but the fixation of nitrogen in carbonaceous material occurs more readily than that of iron, when the sulfur content increases markedly. This is why a steplike trend is observed instead of a simple linear trend. If we now consider the $\mathrm{N} / \mathrm{Fe}$ ratio in relation to the sulfur content remaining in the carbonaceous support, after Fe and nitrogen fixation, we can see that there is a certain proportionality 
Table 2. Summary of Various Textural Parameters Derived from Isotherm Analysis

\begin{tabular}{|c|c|c|c|c|c|c|c|}
\hline & $S_{\mathrm{QSDFT}}\left(\mathrm{m}^{2} \mathrm{~g}^{-1}\right)$ & $S_{\mu}\left(\mathrm{m}^{2} \mathrm{~g}^{-1}\right)$ & $S_{\mathrm{m}}\left(\mathrm{m}^{2} \mathrm{~g}^{-1}\right)$ & $V_{\text {QSDFT }}\left(\mathrm{cm}^{3} \mathrm{~g}^{-1}\right)$ & $V_{\mu}\left(\mathrm{cm}^{3} \mathrm{~g}^{-1}\right)$ & $V_{\mathrm{m}}\left(\mathrm{cm}^{3} \mathrm{~g}^{-1}\right)$ & $V_{\text {tot }}\left(\mathrm{cm}^{3} \mathrm{~g}^{-1}\right)$ \\
\hline SMC & 1296 & 701.7 & 594.2 & 0.898 & 0.235 & 0.662 & 0.995 \\
\hline SMC70 & 1058 & 373.8 & 684.2 & 0.951 & 0.135 & 0.816 & 1.071 \\
\hline SMC50 & 992 & 344.9 & 646.7 & 0.912 & 0.126 & 0.786 & 1.026 \\
\hline SMC30 & 739 & 243.5 & 495.7 & 0.698 & 0.090 & 0.608 & 0.779 \\
\hline $\mathrm{MC}$ & 1277 & 558.3 & 718.7 & 1.304 & 0.209 & 1.095 & 1.554 \\
\hline SMCSt5 & 1191 & 803.5 & 387.6 & 0.695 & 0.247 & 0.448 & 0.831 \\
\hline SMCSt 20 & 1562 & 878.6 & 683.2 & 1.075 & 0.305 & 0.770 & 1.197 \\
\hline SMCSt40 & 1377 & 764.5 & 612.1 & 1.276 & 0.286 & 0.990 & 1.277 \\
\hline SMCSt60 & 1726 & 841.0 & 884.9 & 1.429 & 0.323 & 1.106 & 1.585 \\
\hline
\end{tabular}

Figure $1 \mathrm{~d}$, and this is a further confirmation that the presence of sulfur in the support drives the formation of nitrogen (and possibly $\mathrm{Fe}-\mathrm{N}_{x}$ surface functional groups), as will be seen more specifically later in the text. However, on the sole basis of stoichiometry considerations, Figure $1 \mathrm{c}, \mathrm{d}$ points out that, with iron being the limiting element, most part of nitrogen functional groups are not involved in the $\mathrm{Fe}-\mathrm{N}_{4}$ site, but in other sites that however are known to have an effect on ORR electrocatalysis. ${ }^{45}$

The morphology of the S-doped supports was evaluated through TEM images (Figures 1 and S1). Figure S1a-c shows an array of SMC spheres, with a mean diameter of $\sim 250 \mathrm{~nm}$ and characterized by an internal porous structure conforming to the silica template. Focusing on the border of one sphere, the pore channels can be recognized (Figure S1b). The SMC materials doped with different $S$ amount are very similar in shape and pore structure, attesting the solidity of the adopted hard template synthesis. The steam effect on morphology was also investigated (Figure S1d-f). The spherical shape was maintained even though the carbon particles appear less dense, and in some spheres, the porosity channels disappear or become less ordered, while in other spheres, edges become more fragmented. Therefore, the action of the steam activation is to open up the pore structure, increasing the hierarchy to the detriment of the pore order.

Figure 1 shows TEM images of some $\mathrm{Fe}-\mathrm{N}-\mathrm{C}$ catalysts: the morphology of the support is maintained after the $\mathrm{Fe} / \mathrm{N}$ doping and the pyrolysis treatment and it is evident how the carbon particle dimensions span from hundreds to thousands of nanometers. In fact, the pore channels in Figure 1e of FeSMC are evident, only the sphere borders are jagged and not defined, maybe due to the carbonization of phenanthroline used as a ligand in the iron complex. The spherical structure of FeMC appears quite damaged (Figure $1 \mathrm{~g}, \mathrm{~h}$ ), and some porous carbon sheets are also visible even if not being present in the starting MC. In FeSMCSt $X(X=5,20,40)$ two main structures are visible: one characterized by ordered pores and the other one by disordered pores (Figure 1i-r). Similar structures, even if less ordered, were also observed in FeSMCSt60 (Figure 1q,r). It is worth mentioning that the border of carbon particle not only became more jagged, but the edge erosion extension grows for longer treatment. Very few iron nanoparticles (NPs) are individuated embedded in the carbon structure, and this is reasonable considering the low iron content reached after the acid wash step (Table 1 and Figure $1 \mathrm{i}-\mathrm{r}$ ).

The textural properties, which consider another grade of morphology characterization, were evaluated using $\mathrm{N}_{2}$ adsorption/desorption isotherm, and the data are resumed in Table 2. The isotherms in Figure 2a belong to IV(a) type with (a)

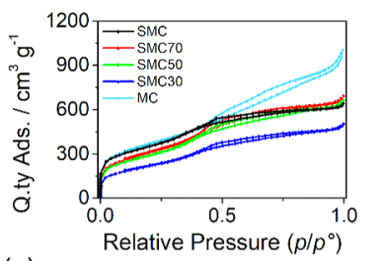

(c)

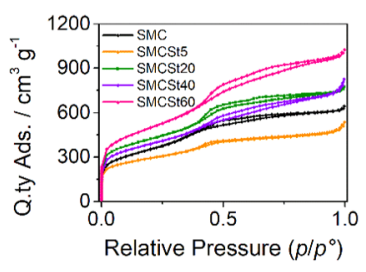

(e)

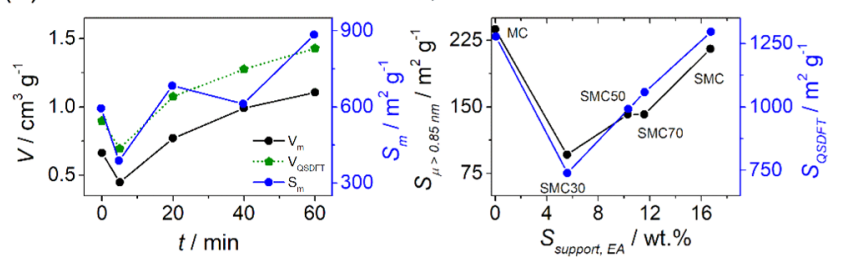

Figure 2. (a) $\mathrm{N}_{2}$ adsorption/desorption isotherms and (b) pore size distribution (PSD) of SMC series with different contents of sulfur. (c) $\mathrm{N}_{2}$ adsorption/desorption isotherms and (d) pore size distribution of SMCSt series. Correlation of textural properties (e) with the steam treatment duration and (f) with the amount of sulfur fixed in the precursors.

an $\mathrm{H} 4$ hysteresis. The adsorption branch follows a hybrid-type I(b)/II isotherm, which presents two main features: (i) a pronounced uptake at a low relative pressure $\left(p / p^{\circ}\right)$ associated with the micropore filling and (ii) a slow gradual increment of $\mathrm{N}_{2}$ adsorbed up to $0.8 \mathrm{p} / \mathrm{p}^{\mathrm{o}}$. ${ }^{46}$ These effects are typical of a micro-mesoporous material.

The sulfur content in the SMCX series seems to affect the specific surface area $\left(S_{\mathrm{QSDFT}}\right)$ : i.e., the higher the sulfur, the higher the microporous surface area $\left(S_{\mu}\right)$. The sample obtained from sucrose alone $(\mathrm{MC})$ has a surface area close to the support obtained from pure DBT (SMC), but the micro- and mesoporous surfaces ratio is different. In fact, $\mathrm{MC}$ has a lower $S_{\mu}$ and a higher $S_{\mathrm{m}}$ compared to SMC, which slightly changes the respective isotherms up to $0.5 p / p^{\circ}$, i.e., the adsorption branch at $0.5 p / p^{\circ}$ increases faster in MC than in SMC. From 0.5 onward, the evolution of hysteresis and gas adsorption is indeed different: SMC has an $\mathrm{H} 4$ hysteresis, where the desorption branch approaches to the adsorption one at $0.45 \mathrm{p} /$ $p^{\circ}$ (the characteristic cavitation pressure), while MC features a 
mixed hysteresis between $\mathrm{H} 3$ and $\mathrm{H} 4$ without a sharp stepdown of the desorption resulting in a higher total pore volume. This difference is due to the porous structure of the supports: SMC has open and restricted pores, instead MC has a more open and accessible surface. The isotherms of the other supports (SMC70, SMC50, and SMC30) are more similar to SMC than to MC. To obtain the porous parameters, namely, the pore size distribution (PSD), a slit/cylindrical/spherical QSDFT adsorption model was applied on experimental data, ${ }^{47-49}$ and it was chosen considering both the hysteresis features and the structure of the P200 silica template. Comparing the pore size distribution between SMC and MC (Figure 2b), it is possible to observe that they have similar micropore size peaked at $1.09 \mathrm{~nm}$, while they differ for the size of mesopore. MC has a shoulder toward higher values compared to SMC with two peaks at 6.4 and $8.5 \mathrm{~nm}$. Reducing the content of DBT precursors, the microporous volume is reduced, and the width increases slightly up to 1.15 $\mathrm{nm}$, while the mesopores are not affected.

The effect of steam on textural properties was also evaluated. The shape of the isotherm is not affected by steam and so the type (IV(a) type) remains the same, while the hysteresis shape change (Figure 2c). In general, steam opens the structure acting on the mesopores, which are centered around $6 \mathrm{~nm}$ as shown in Figure 2d. The microporous surface area lies between 804 and $879 \mathrm{~m}^{2} \mathrm{~g}^{-1}$, while the mesoporous area is increased from 594 to $885 \mathrm{~m}^{2} \mathrm{~g}^{-1}$ for SMC and SMCSt60, respectively. SMCSt5 does not present an increment of surface area and its pore size distribution is less broad with pores of 1 and $6 \mathrm{~nm}$. In this case, steam does not affect the texture, but it rather removes some amorphous carbon, as it will be shown later on in the text when discussing the Raman spectrum. SMCSt20 hysteresis is characterized by two step-downs in the desorption branch at 0.6 and $0.4 p / p^{\circ}$, which could identify two types of ink-bottle shape pores. ${ }^{46,50,51}$ Increasing the treatment time, in SMCSt60, the first step-down at $0.6 p / p^{\circ}$ becomes less evident according to the enlarging of pore size from 7 to $20 \mathrm{~nm}$, as demonstrated by pore size distribution in Figure 2d. SMCSt 40 lies out of trend with a decrease of $S_{\mathrm{QSDFT}}$ and $V_{\mu}$, but a clear explanation cannot be given about this.

Figure $2 \mathrm{e}$ reports some textural properties as a function of the steam treatment duration, and it is evident that for $\mathrm{St}=5$ min, there is a diminution of the mesopore surface and volume that was explained considering a possible clogging of the pore structure. However, for more extensive treatments, $V_{\mathrm{m}}$ and $S_{\mathrm{m}}$ increase with increasing treatment duration, with the sole exception of the point at $\mathrm{St}=40 \mathrm{~min}$, for which there is no easily interpretable decrease in the sole mesopore surface.

Figure $2 \mathrm{f}$ shows that as the content of sulfur, and therefore of DBT, increases, there is an almost linear increase in both $S_{\mathrm{QSDFT}}$ and $S_{\mu}$. It is interesting to note that the sample prepared from sucrose alone has comparable $S_{\mathrm{QSDFT}}$ and $S_{\mu}$ to those of SMC, and therefore it is the different ratio of the two precursors that enables the tuning of micropore size (here greater than $0.85 \mathrm{~nm}$ ). Therefore, sulfur has a dual effect: (i) it is able to dope the carbonaceous material and (ii) it has a porogenic action. ${ }^{8}$

The graphitization degree was evaluated on the $\mathrm{Fe}-\mathrm{N}-\mathrm{C}$ catalysts by means of Raman analysis. These materials do not present defined second-order Raman spectra (2400-2700 $\mathrm{cm}^{-1}$ region), and only a smeared flat band is present, which overlaps with the background noise (Figure 3a,b). It is clear that even if the sulfur content significantly differs among the
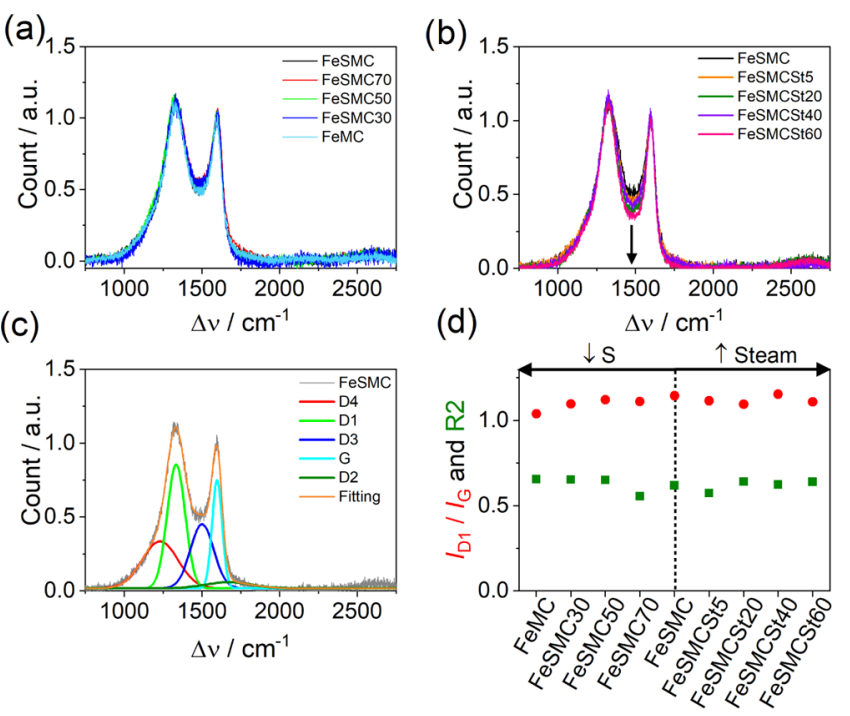

Figure 3. (a, b) Comparison of Raman spectra for the two sets of samples, (c) deconvolution of Raman spectrum using gaussian peak functions for FeSMC catalyst, and (d) $I_{\mathrm{D} 1} / I_{\mathrm{G}}$ ratio and $R_{2}$ parameters for the different catalysts.

FeSMCX samples, this does not lead to substantial changes, as confirmed by the superimposable Raman spectra reported in Figure 3a. The spectra deconvolution in the first-order region between 1100 and $1700 \mathrm{~cm}^{-1}$ (Figure 3c) was performed using five gaussian bands: $D_{4}, D_{1}, D_{3}, G$, and $D_{2}$, with the latter fixed at $1620 \mathrm{~cm}^{-1}$, as reported by Sadezky et al. ${ }^{52}$ The position of the main bands $D 1$ and $G$ did not significantly change passing from FeSMC to FeMC (Table S1). The $A_{\mathrm{D} 1} / A_{\mathrm{G}}$ and $I_{\mathrm{D} 1} / I_{\mathrm{G}}$ ratios are close to 2.0 and 1.1, respectively, and that is an indication of carbon material with a poor ordered structure (Figure 3d). ${ }^{53}$ A further confirmation of this is the parameter $R_{2}$, which for poorly organized carbon materials assumes a value $>0.5$, while $R_{2}<0.5$ is indicative of highly graphitized carbons, where $R_{2}=D_{1} /\left(G+D_{1}+D_{2}\right)$ is the ratio between the area of $D_{1}$ peak and the sum of $G, D_{1}$ and $D_{2}$ areas (Table $S 1$ ). In the present case, $R_{2}$ remains essentially constant passing from samples with higher to low sulfur content. ${ }^{54}$ The high $R_{2}$ and $I_{\mathrm{D} 1} / I_{\mathrm{G}}$ ratio are to ascribe to sulfur, which has a larger atomic radius than carbon so that the incorporation of sulfur induces more strain and defect sites in the carbon matrix, thus resulting in a lower graphitization degree, and to smaller carbon crystallite dimensions. ${ }^{55,56}$ A slightly different picture emerges from the FeSMCSt series where the steam treatment leads to a $13 \%$ reduction of the D3 band area, which accounts for amorphous carbon (Figure $3 \mathrm{~b}$ and Table $\mathrm{S} 1$ ). However, the $I_{\mathrm{D} 1} / I_{\mathrm{G}}$ ratio still remains high, stabilizing around $1.1\left(A_{\mathrm{D} 1} / A_{\mathrm{G}}\right.$ around 2.1), and $R_{2}$ stems between 0.55 and 0.65 . Both values are typical for a low-ordered carbon structure (Figure $3 \mathrm{~d}$ ). ${ }^{57}$ Therefore, it may be inferred that all of the catalysts possess similar properties in terms of graphitization degree (small carbon crystallites dispersed in amorphous carbon), but they differ in terms of sulfur content and textural properties.

Catalyst surface compositions were determined by XPS; an example of XPS survey, $\mathrm{N} 1 \mathrm{~s}, \mathrm{C} 1 \mathrm{~s}$, and $\mathrm{S} 2 \mathrm{p}$ are reported in Figure 4, whereas data of speciation are resumed in Table S2. XPS analysis confirmed that a high sulfur content in the initial support allows us to fix a higher percentage of nitrogen in the carbon surface, the opposite thing happens for iron, which actually decreases in content with the increase of the initial 
(a)

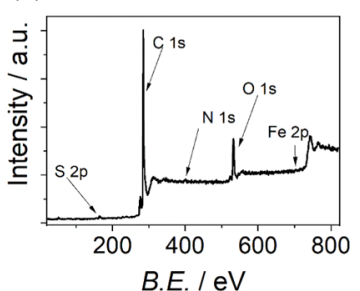

(c)

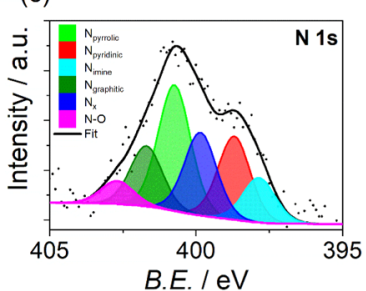

(e)

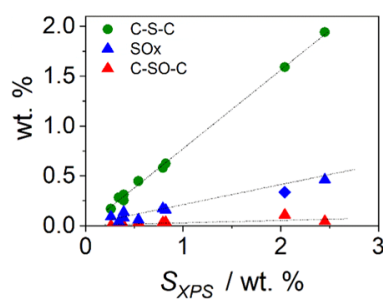

(b)

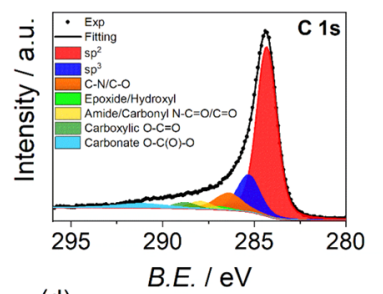

(d)

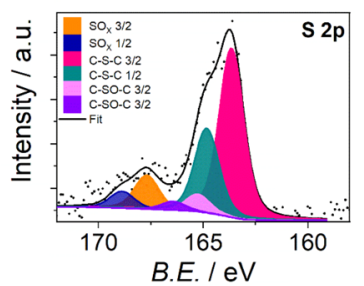

(f)

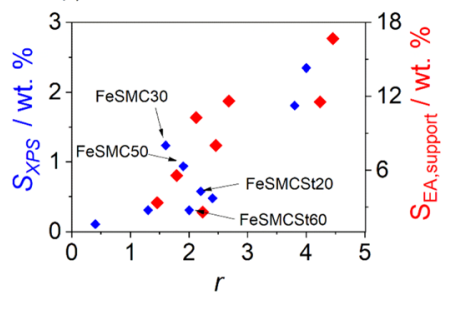

Figure 4. (a) Survey of FeSMC. Examples of high-resolution corelevel XPS spectra of (b) C 1s, (c) N 1s and (d) S 2p of FeSMC. (e) Variation of different sulfur components $\left(\mathrm{C}-\mathrm{S}-\mathrm{C}, \mathrm{SO}_{x}\right.$, and $\mathrm{C}-\mathrm{SO}-$ C) with the total sulfur content determined by XPS measurements and $S 2 p$ deconvolution. (f) Variation of $r$ parameter with the sulfur content determined by elemental analysis (red marks) and XPS (blue marks); $r$ parameter is calculated according to equation $r=(\mathrm{C}-\mathrm{S}-$ $\mathrm{C}) / \mathrm{Fe}$ (atom \%) and accounts for the ratio between the thiophenic functional groups and iron content.

sulfur content, as already pointed out in the previous paragraph.

Figure $4 \mathrm{~b}$ shows the $\mathrm{C} 1 \mathrm{~s}$ spectra of analyzed samples. The $\mathrm{C} 1 \mathrm{~s}$ spectra were fitted according to refs $23,58-61$. The main carbon component at $\mathrm{BE}$ of $284.3-284.4 \mathrm{eV}$ is attributed to $\mathrm{C}$ $\mathrm{sp}^{2}$. At higher BE $(285.4 \mathrm{eV})$, the peak represents the $\mathrm{sp}^{3} \mathrm{C}-\mathrm{C}$ bond. There is also a substantial amount of carbon bound to nitrogen or/and to oxygen (peak at $286.4 \mathrm{eV}$ ). Peaks at BEs higher than $286.4 \mathrm{eV}$ are due to carbon species bound to oxygen $(\mathrm{C}=\mathrm{O}, \mathrm{O}-\mathrm{C}=\mathrm{O}, \mathrm{O}-\mathrm{C}(\mathrm{O})-\mathrm{O})$ or oxygen and nitrogen $(\mathrm{C}-\mathrm{N}=\mathrm{O}, \mathrm{N}-\mathrm{C}=\mathrm{O})$. The peak at $291.1 \mathrm{eV}$ is due to shakeup satellite $\left(\pi-\pi^{*}\right)$. In the literature, the position of the $\mathrm{C}-\mathrm{S}-\mathrm{C}$ bond ranges from 285.0 to $286.0 \mathrm{eV}^{62-66}$ moreover taking into account that samples with $\mathrm{Fe}$ and $\mathrm{S}$ contain less than 1 atom $\%$ of sulfur, which would account for less than 2 atom \% of fraction of $\mathrm{C} 1$ s peak (assuming that one $\mathrm{S}$ is bounded to two $\mathrm{C}$ ). Therefore, the assignment of the $\mathrm{C}-$ $\mathrm{S}-\mathrm{C}$ position in the analyzed sample is not trivial. In the literature, ${ }^{62}$ in a sample containing ca. $40 \%$ of $\mathrm{C}-\mathrm{S}-\mathrm{C}$, the $\mathrm{C}$ 1 s position assigned to $\mathrm{C}-\mathrm{S}-\mathrm{C}$ is at $285.3 \mathrm{eV}$, while $\mathrm{sp}^{2} \mathrm{C}$ is at $284.3 \mathrm{eV}$; therefore, it can be assumed that the $\mathrm{C}-\mathrm{S}-\mathrm{C}$ peak overlaps with the $\mathrm{C} \mathrm{sp}^{3}$ component.

The surface content of nitrogen determined by the XPS analysis well matches with the bulk content determined by the elemental analysis, confirming a homogeneous functionalization of the carbonaceous substrate. ${ }^{53}$ The $\mathrm{N} 1 \mathrm{~s}$ high-resolution signal was fitted in several components including: ${ }^{67} \mathrm{~N}$-imine
(397.8 eV), $\mathrm{N}$-pyridinic $(398.8 \mathrm{eV}), \mathrm{N}$-amine and $\mathrm{N}_{x}(399.9$ eV), $\mathrm{N}$-pyrrolic $(400.7 \mathrm{eV}), \mathrm{N}$-graphitic $(401.7 \mathrm{eV})$, and $\mathrm{N}$ oxide $(402.7 \mathrm{eV})$ (Figure $4 \mathrm{c}$ ). Pyrrolic nitrogen is distinguished among all of the other functional groups because it is the most abundant. Conversely, the $\mathrm{N}_{x}$-Fe functional group, which is supposed to be the most important active site for ORR, reaches its highest value (25.1 wt \%) in FeSMCSt40. However, this result must be taken with caution since $\mathrm{N}_{x}$-Fe and $N$-amine signals fall at similar BE, making XPS analysis not fully reliable in quantifying $\mathrm{N}_{x}$-Fe active sites, that is why sometimes only one component is used. The $S 2 p$ signal for sulfur is deconvoluted into three species: S-thiophene (C-SC) at $163.6 \mathrm{eV},{ }^{68}$ sulfoxide $(\mathrm{C}-\mathrm{SO}-\mathrm{C})$ at $165.3 \mathrm{eV}$, and Soxide (oxidized $\mathrm{S}$ or $\mathrm{SO}_{x}$ ) at $167.6 \mathrm{eV}$ (Figure 4d). ${ }^{69}$ Each peak of sulfur-based functionalities is split into two spin-orbit components, namely, $3 / 2$ and $1 / 2$. The percentage of the different species are reported in Table S2. It is proposed in the literature that the catalytic activity of the $\mathrm{Fe}-\mathrm{N}_{x}$ site can be tuned introducing electron-withdrawing/-donating groups close to the active site, but which of the two effects actually determines the positive influence on the activity of the $\mathrm{Fe}-\mathrm{N}_{x}$ site toward the ORR is the subject of conflicting and even antithetical opinions. ${ }^{36,70}$ In fact, Mun et al. explained using DFT and XANES analysis that in catalysts with a high ratio of oxidized $\mathrm{S}\left(\mathrm{SO}_{x}\right) /(\mathrm{C}-\mathrm{S}-\mathrm{C})$, there is an electron-withdrawing effect that removes charge density from $\mathrm{Fe}-\mathrm{N}_{x}$, decreasing the d-band center so that the intermediate adsorption energy becomes lower, thereby facilitating the ORR. ${ }^{36,71}$ Conversely, $\mathrm{Ni}$ et al. found that thiophene functionality donates electron density to the carbon plane thanks to its lone pair, and this could tune $\mathrm{Fe}-\mathrm{N}_{4}$ activity for the ORR. ${ }^{72}$ Therefore, the activity of $\mathrm{Fe}-\mathrm{N}_{x}$ sites could be controlled by changing the extent of the electronic effect. ${ }^{36}$ Moreover, the position of the sulfur is important, and it is beneficial if located at least $7.3 \AA$ away from iron active site. Figure $4 \mathrm{e}$ shows that the percentage of thiophene-like sites increases as the whole sulfur content in the carbonaceous support increases, as does the $\mathrm{SO}_{x}$ group, even though the latter is always present in much lower percentages. $\mathrm{Ni}$ et al. also suggest that the relative ratio of sulfur and iron is crucial to the coordination configurations of the active sites, which directly determine the ORR activity. To do so, they introduced a parameter $r=(\mathrm{C}-\mathrm{S}-\mathrm{C}) / \mathrm{Fe}$ (atom $\%)$ that accounts for the ratio between the thiophenic functional groups and iron content, and found an optimal ratio of 1.81 , i.e., the higher catalytic activity in terms of $E_{1 / 2}$ was found in those catalysts where there were almost two thiophenic groups per iron atom. It is worth noting that $r$ increases with increasing sulfur content in the carbon support (Figure 4f) and in particular from 0.4 to 4.3 passing from FeMC to FeSMC (Table S2), i.e., from the support with the lowest amount of sulfur to the one with the highest amount, where FeSMC50 assumes almost the optimal value $(r=1.9)$, and therefore, it is expected to perform better than the other catalysts. On the other hand, the samples with excess sulfur content are expected to not perform properly since the formation of $\mathrm{FeS}_{x}$ species, which according to the literature are removed after acid washing, competes with $\mathrm{Fe}-\mathrm{N}_{x}$ formation. $^{72}$ Finally, looking to the survey (Figure $4 \mathrm{a}$ ), no evident peak of Silicon was observed, confirming the effectiveness of the carbon etching process.

Cyclic voltammetry and linear sweep voltammetry at RRDE were employed to evaluate the effect of different sulfur content and textural properties on the catalytic activity of the different 
catalysts (Figure 5). It is worth noting that FeSMC and FeMC have almost superimposable electrochemical behavior with

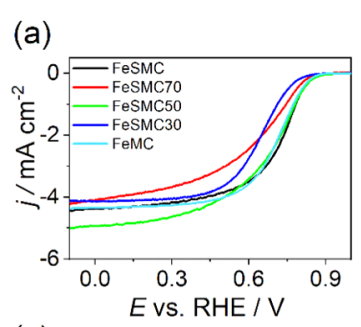

(c)

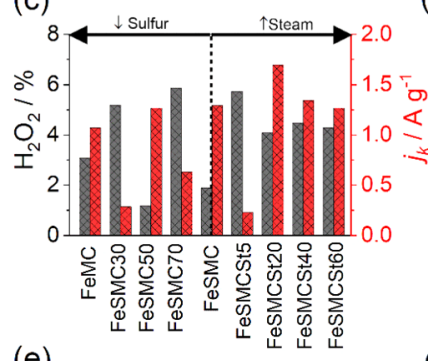

(e)

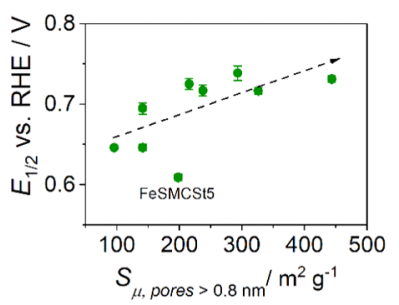

(b)

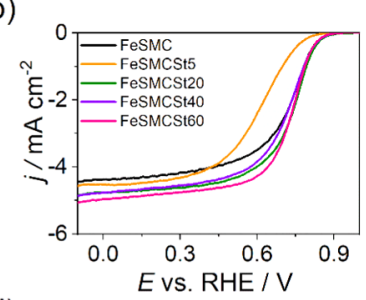

(d)

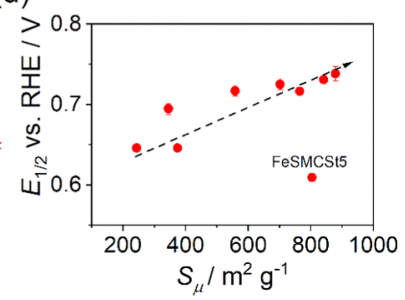

(f)

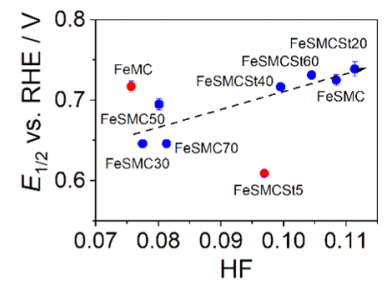

Figure 5. (a, b) LSV recorded at $1 \mathrm{mV} \mathrm{s}^{-1}$ in $\mathrm{O}_{2}$-saturated electrolyte $\left(0.5 \mathrm{M} \mathrm{H}_{2} \mathrm{SO}_{4}\right)$ at $1600 \mathrm{rpm}$; (c) kinetic current density determined at $0.8 \mathrm{~V}$ vs $\mathrm{RHE}$ and $\mathrm{H}_{2} \mathrm{O}_{2}$ generation determined at $0.2 \mathrm{~V}$ vs RHE for different catalysts. Variation of the half-wave potential with different textural properties: (d) surface area of micropore, (e) surface area of micropore bigger than $0.8 \mathrm{~nm}$, and (f) hierarchical factor (HF). In $(\mathrm{d}-\mathrm{f})$, dotted lines are only intended to guide the eye.

very similar $E_{1 / 2}$ and limiting current $j_{\mathrm{L}}$ for $\mathrm{O}_{2}$ reduction process. FeSMC50 shows a similar electrochemical performance even if a higher $j_{\mathrm{L}}$ is reached (Figure 5a). FeSMC, FeSMC50, and FeMC have also similar $j_{\mathrm{k}}$ at $0.85 \mathrm{~V}$ vs RHE, and the number of transferred electrons $(n)$ is close to 4 with ca. $6 \%$ of maximum peroxide production $\left(\% \mathrm{H}_{2} \mathrm{O}_{2}\right.$ in Figure 5c). In the same series, FeSMC30 and FeSMC70 have definitively lower performance (Figure $5 \mathrm{a}$ ) in terms of $E_{1 / 2}$ and $j_{\mathrm{k}}$ and the selectivity is more or less similar (Table S3). So, there appears to be no direct dependence between $E_{1 / 2}$ or $j_{\mathrm{k}}$ and the sulfur content determined by elemental analysis or via XPS in the final catalyst. Even the speciation into $(\mathrm{C}-\mathrm{S}-\mathrm{C})$ or $\mathrm{SO}_{x}$ groups does not allow for any correlation, and this is evident since both defects increase in content as the total sulfur content increases, as seen in the previous paragraph. Not even the volcano-type dependence of $E_{1 / 2}$ from $(\mathrm{C}-\mathrm{S}-\mathrm{C}) / \mathrm{Fe}$ ratio proposed by $\mathrm{Ni}$ et al. finds confirmation in the sulfur-doped series. $^{72}$

The samples treated with steam show, with the exception of FeSMCSt5, the same behavior in the kinetic-controlled zone, while they differ in the diffusive-controlled zone by a different limiting current, i.e., the sample with a prolonged steam treatment shows a higher limiting current (Figure 5b). This can be associated with the opening of the pore structure, which results in a better utilization of the active sites and allows the
FeSMCSt60 sample to become one of the best catalysts, despite a sulfur content that decreases dramatically after steam activation (Figure 5c and Table S3). The exceptional behavior of FeSMCSt5 can be explained considering that such brief steam treatment does not allow an effective pore opening but the sole partial oxidation of the most reactive amorphous carbon, and this is confirmed by the reduction of mesoporous volume from 0.662 to $0.448 \mathrm{~cm}^{3} \mathrm{~g}^{-1}$. ${ }^{26}$ Thus, at first sight, sulfur does not appear to have a univocal effect on the catalytic properties of the material, but it is worth checking whether or not the textural properties, which depend, as we have seen, on the sulfur content, can have an effect on the performance of the material. In fact, textural properties are well known to contribute to the final activity, determining the exposure of active sites and consequently the effectiveness of mass transport. ${ }^{23}$ Figure $5 \mathrm{~d}$ shows that there is a good correlation between the half-wave potential and the micropore surface area, i.e., $E_{1 / 2}$ becomes more positive (the catalytic activity increases) when the micropore surface area increases. It is known that micropore surface is fundamental to increase the activity because they are involved in the formation of $\mathrm{Fe}-\mathrm{N}_{x}$ centers. ${ }^{73}$ FeSMCSt5 does not fit in the trend, but if the sole pore larger than $0.8 \mathrm{~nm}$ is considered, there seems to be a better congruence with the other catalysts (Figure 5e). Furthermore, $E_{1 / 2}$ shows a good correlation also with the hierarchical factor (HF) (Figure 5f), which is a descriptor of how much interconnected are micropores and mesopores. HF is expressed by the equation

$$
\mathrm{HF}=\left(V_{\mu} \times S_{\mathrm{m}}\right) /\left(V_{\mathrm{TOT}} \times S_{\mathrm{QSDFT}}\right)
$$

where $V_{\mu}$ and $V_{\text {TOT }}$ are the volume of micropore and the total volume pore, respectively, while $S_{\mathrm{m}}$ and $S_{\mathrm{QSDFT}}$ are the surface area of mesopore and the total surface area determined by the quenched-solid density functional theory model, respectively. ${ }^{24}$ In the best catalysts, the HF factor is maximized by increasing the surface area of the mesopores without extremely decreasing the volume of the micropores, with the aim of improving the efficiency of reagent and product transport to the active site. In the present case, the catalysts showing a maximized HF are those that showed improved catalytic activity, such as FeSMC or FeSMCSt20, while the worst catalysts are those with the lowest HF (Figure 5f), although the sulfur content of the carbon support or remaining in the catalyst may be higher than in other, better-performing catalysts (Tables 1 and S2). Therefore, not only microstructure is important, but also mesostructure is useful to obtain an active catalyst toward the ORR.

To extend the electrochemical analysis and to compensate the uncertainty of XPS regarding the capability of identifying and quantify $\mathrm{Fe}-\mathrm{N}_{x}$ sites, we performed nitrite stripping to determine the SD and the turnover frequency (TOF) (Figure $6 \mathrm{a}, \mathrm{b}){ }^{41,74,75}$ This procedure employs $\mathrm{NO}_{2}{ }^{-}$as probe molecules able to reversibly poisoning $\mathrm{Fe}-\mathrm{N}_{x}$ sites by the formation of a NO-Fe bond. The electrochemical stripping of the nitrosyl ligand produces ammonia and the free $\mathrm{Fe}-\mathrm{N}_{x^{*}}{ }^{75}$ It is important to underline how, during the poisoning step, the activity is not totally suppressed because of the presence of other active sites such as nitrogen functional groups, which catalyze the different steps of the oxygen reduction reaction. ${ }^{28}$ Furthermore, SD determined by the NO method is 2 to 8 times lower than that derived from $\mathrm{CO}$ cryo-chemisorption, so it was proposed that $\mathrm{SD}_{\text {mass }}\left(\mathrm{NO}_{2}^{-}\right)$represents the lower bound of the $\mathrm{SD}_{\text {mass }}$ of $\mathrm{Fe}-\mathrm{N}-\mathrm{C}$ catalysts. 

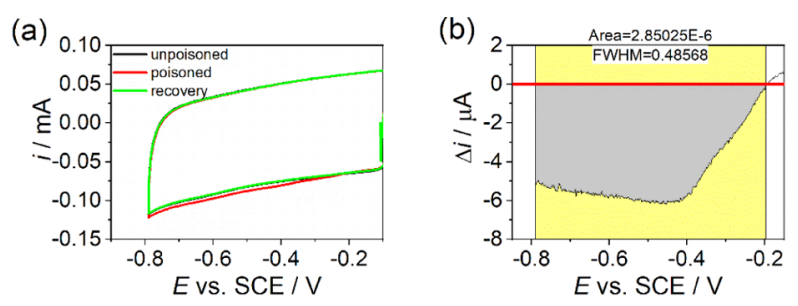

(c)

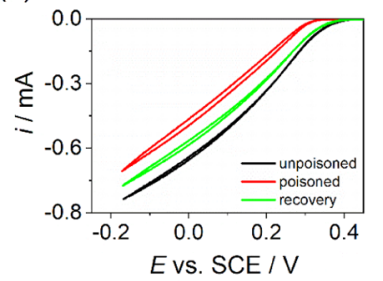

(e)

(d)

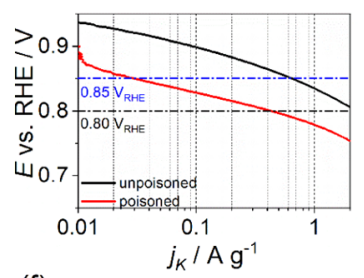

(f)

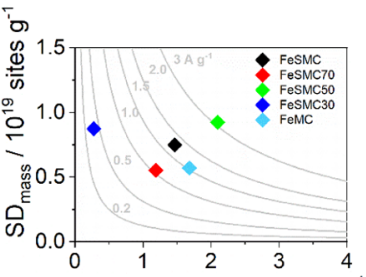

TOF $0.8 \mathrm{~V}_{\mathrm{RHE}}$ / electrons sites ${ }^{-1} \mathrm{~s}^{-1}$ (g)
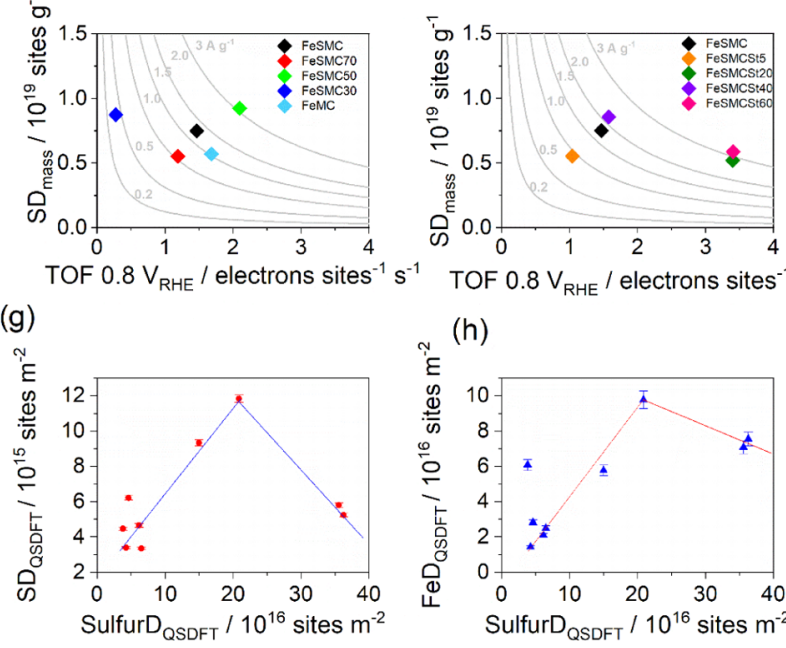

TOF $0.8 \mathrm{~V}_{\mathrm{RHE}}$ / electrons sites ${ }^{-1} \mathrm{~s}^{-1}$

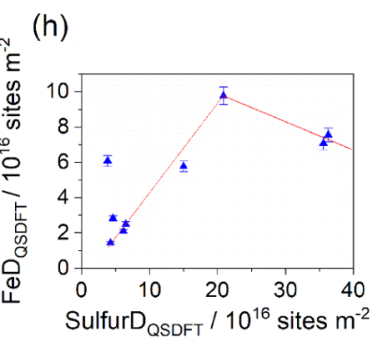

Figure 6. (a) Nitrite stripping and recovered CVs of FeSMC recorded in Ar-saturated electrolyte at $10 \mathrm{mV} \mathrm{s}^{-1}$, (b) magnification of the stripping area integrated for the site density determination, (c) LSV recorded before, during, and after poisoning at $1600 \mathrm{rpm}$ and $5 \mathrm{mV}$ $\mathrm{s}^{-1}$ in $\mathrm{O}_{2}$-saturated electrolyte, and (d) Tafel plots for the poisoned and recovered catalyst. Activity map of (e) FeSMCX series and (f) FeSMCStY series; gray lines represent the iso-current line, which is a hyperbole according to eq 5 . (g) Variation of $\mathrm{Fe}-\mathrm{N}_{x}$ site density with respect to sulfur site density (SulfurD) in the catalysts. (h) Variation of $\mathrm{Fe}$ site density ( $\mathrm{FeD}$ ) with respect to sulfur site density in the catalysts. In ( $\mathrm{g}$ ) and $(\mathrm{h})$, dotted lines are only intended to guide the eye.

Figure $6 \mathrm{c}$ shows the activity toward the ORR of FeSMC at the different steps of the protocol: unpoisoned (black), poisoned by nitrite adsorption (red), and recovery (green) after nitrite reduction. The CVs in the potential range of nitrite reduction are reported in Figure 6a. The activity is almost recovered after nitrite stripping; in fact, the current profiles between -0.2 and $-0.8 \mathrm{~V}$ vs SCE become superimposable. SD and TOF were calculated from the stripping charge obtained from the current difference between the CVs of poisoned and recovered samples according to eqs 4 and 5 , respectively. The stripping current for FeSMC is plotted in Figure $6 \mathrm{~b}$, while Figure $6 \mathrm{~d}$ compares the kinetic current density of unpoisoned and poisoned samples at 0.80 and $0.85 \mathrm{~V}$ vs RHE. This protocol was applied for all of the catalysts prepared, and the results are summarized in Table S4. FeSMC50 shows the highest SD $\left(0.93 \times 10^{19}\right.$ sites $\left.\mathrm{g}^{-1}\right)$ of all of the investigated catalysts and the highest TOF $\left(2.10 \mathrm{~s}^{-1}\right)$ among the FeSMCX series. Among all sulfur-based catalysts, the highest TOF values are observed for the steam-activated samples, FeSMCSt20 and FeSMCSt60: TOF $=3.4 \mathrm{~s}^{-1}$ at $0.8 \mathrm{~V}$ vs RHE (Figure 6e,f and Table S4).

The reactivity maps reporting the $\mathrm{SD}$ variation versus the TOF are shown in Figure 6e,f. In these maps, each catalyst belongs to "iso-mass activity" hyperbolic curve, where the SD is normalized by the mass of catalysts [sites $\mathrm{g}^{-1}$. The experimental data cannot be univocally interpreted on the basis of the sole sulfur content or textural properties, i.e., no clear correlation is individuated between SD or TOF and the sulfur content or the micropore surface. However, it can be observed that the catalysts prepared using a support with higher sulfur content show both high SD and TOF (FeSMC50 and FeSMC), whereas high TOFs are observed in those catalysts prepared using supports having high mesopore surface rather high sulfur content (FeSMCSt20 and FeSMCSt60). In fact, steam acts principally on mesoporosity, which is not involved in the formation of $\mathrm{Fe}-\mathrm{N}_{x}$ centers. $^{73}$ Furthermore, the catalysts containing the highest values of SD (FeSMC50) does not coincide with the catalysts with the most positive $E_{1 / 2}$ (FeSMCSt20) for the $\mathrm{O}_{2}$ reduction process. Therefore, this highlights that $\mathrm{Fe}-\mathrm{N}_{x}$ is important as active sites, but the activity depends also on other types of sites, which are more favorably utilized in those catalysts having high $\mathrm{HF}$ or micropore surface (Figure 5d,e). This is confirmed by the fact that iron percentage active for the ORR (utilization factor) increases in the steam-treated catalysts since the steam activation helps in opening up the structure, allowing a better access of electrolyte to the iron sites (Table S4). ${ }^{23}$ One last comment can be made considering Figure $6 \mathrm{~g}, \mathrm{~h}$. Figure $6 \mathrm{~g}$ shows the plot between the $\mathrm{Fe}-\mathrm{N}_{x}$ site density and the "sulfur site density", i.e., the number of sulfur functional groups (or sulfur atoms) per $\mathrm{m}^{2}$ of catalyst determined by $\mathrm{N}_{2}$ adsorption/ desorption. The plot has a volcano-type shape where the highest number of active sites is determined in the catalyst (FeSMC50) having not too low or too high sulfur content, i.e., the optimal Sulfur/Fe-N $\mathrm{N}_{x}$ ratio (SulfurD/SD) is close to 18 . As seen before, FeSMC50 has also a $\mathrm{C}-\mathrm{S}-\mathrm{C} / \mathrm{Fe}$ ratio value very close to $r=1.8$ determined by $\mathrm{Ni}$ et al. as to be the optimal one. ${ }^{72}$ However, it is worth mentioning that the sample having the best Sulfur/ $\mathrm{Fe}-\mathrm{N}_{x}$ ratio is one of the most active, but not the most active at all because the HF is not optimal (Figure 5f). It is curious to observe that if instead of $\mathrm{Fe}-\mathrm{N}_{x}$ site density a more general $\mathrm{Fe}$ site density is considered, i.e., the number of iron atoms (determined by XPS) per $\mathrm{m}^{2}$ of catalyst, the trend has again a volcano shape, but the best ratio fairly matches with the 1.8 value determined by $\mathrm{Ni}$ et al. ${ }^{72}$ (Figure $6 \mathrm{~h}$ ). This is indicative that, in the bestcase scenario, roughly $10 \%$ of iron sites are actively utilized for catalyzing the ORR. The different value between SulfurD/Fe$\mathrm{N}_{x} \mathrm{SD}$ and SulfurD/FeD is strictly correlated to the utilization factor, i.e., not all of the available iron sites are accessible and involved in ORR catalysis and part of it is not even in the $\mathrm{Fe}-$ $\mathrm{N}_{x}$ form. As further information, utilization factors calculated considering the Fe determined by ICP analysis are reported in Figure S4.

A last comment must be made about the possible electronic effect induced by the thiophenic functional groups on the $\mathrm{Fe}-$ $\mathrm{N}_{x}$ sites, since the electron donation from thiophenic groups to the surrounding $\mathrm{Fe}-\mathrm{N}_{x}$ sites would modify the electronic structure of $\mathrm{Fe}-\mathrm{N}_{x}$. Figure $\mathrm{S} 2$ reports the $\mathrm{S} 2 \mathrm{p}$ spectra for 
FeSMC, FeSMCSt20, FeSMC50, and the sulfur-doped carbon support SMC taken as reference. The $\mathrm{Fe} 2 \mathrm{p}_{3 / 2}$ XPS spectrum was of no help for the discussion since the very low concentration of iron does not allow a meaningful deconvolution. It should be noted that the $S 2 p$ peak of thiophenic sulfur in FeSMC50, which contain the highest $\mathrm{Fe}-$ $\mathrm{N}_{x}$ sites, displayed a $0.2 \mathrm{eV}$ positive shift compared with $\mathrm{S} 2 \mathrm{p}$ peak in SMC (Figure S2), and a value less than $0.1 \mathrm{eV}$ is observed for FeSMC, which is the sample with the highest sulfur content. The observed BE shifts are too low to claim a sensitive electronic effect even if it cannot be excluded. However, these values must be taken with caution since they are of the same magnitude of the instrumentation sensitivity and the deconvolution loses its meaning when the sulfur content decreases far below $1 \%$ as in the case of FeSMC50. Therefore, we can conclude attesting that a suitable sulfur/iron ratio is important for the formation of $\mathrm{Fe}-\mathrm{N}_{x}$ active site; however, this does not directly translate the catalysts with the highest accessible $\mathrm{Fe}-\mathrm{N}_{x} \mathrm{SD}$ in the most active catalysts, unless the textural properties are also optimized, i.e., there must be an optimized hierarchical porosity that allows better use of the active sites. Furthermore, even if we cannot exclude the presence of an electronic effect, we retain that other effects such as the hierarchical pore structures or the presence of a different content of $\mathrm{Fe}-\mathrm{N}_{x}$ active sites prevail for determining the final catalytic activity since the TOF, $j_{\mathrm{k}}$, and $E_{1 / 2}$ do not change with increasing sulfur content.

\section{CONCLUSIONS}

In this work, we have simultaneously evaluated the effect of sulfur and textural properties on the formation of $\mathrm{Fe}-\mathrm{N}_{x}$-type sites and, in general, on the catalytic activity of the prepared materials toward the oxygen reduction reaction. Five $\mathrm{Fe}-\mathrm{N}-\mathrm{C}$ catalysts were prepared from a carbonaceous support with different sulfur contents in the range 1-16 wt \%. In other five catalysts, the effect of micro- and mesoporosities was evaluated by treating the carbonaceous support with steam at high temperatures so that the resulting $\mathrm{Fe}-\mathrm{N}-\mathrm{C}$ catalysts resulted in similar sulfur content but different textural properties (surface area varying from 1296 to $1726 \mathrm{~m}^{2} \mathrm{~g}^{-1}$ ). Fe-N-C catalysts were prepared by thermal treatment of mesoporous carbons with different sulfur content and $\mathrm{Fe}(\mathrm{Phen})_{3} \mathrm{Cl}_{2}$, which served as iron and nitrogen precursors. Crossing the data of EA, ICP, XPS, and $\mathrm{N}_{2}$ adsorption/desorption characterization with the electrochemical data for the oxygen reduction action and the SD determination, it was evaluated that there is no obvious dependence of the catalytic activity from the sulfur content, i.e., electronic effects induced by sulfur functional groups on iron sites appear to be not relevant. This was also confirmed by comparing the S $2 p$ XPS spectra of different catalysts with the signal of the SMC carbon precursor. A very small shift $(\leq 0.2 \mathrm{eV})$ to higher binding energy was observed, attesting that if an electronic effect is present, it is of small entity and is not expected to affect the catalytic activity of Fe$\mathrm{N}_{x}$ sites. On the contrary, the surface area of micropores and more generally on the HF factor, which defines an optimal ratio between area and surface of micro and mesopores, are more determinant for the electrocatalytic activity. It was found that the sulfur present in the synthesis of the carbonaceous material facilitates the formation of micro- and mesopores, and the sulfur remaining in the mesoporous carbon support facilitates the fixation of nitrogen functional groups, which like $\mathrm{Fe}-\mathrm{N}_{x}$ centers are active or at least make active the nearby carbon atoms to the ORR. It has also been shown that the sulfur present in the carbonaceous support facilitates the formation of $\mathrm{Fe}-\mathrm{N}_{x}$ centers, but that this occurs for not too elevated sulfur content, otherwise $\mathrm{FeS}_{x}$ formation results in an inevitable decrease in the $\mathrm{Fe}-\mathrm{N}_{x}$ yield. It is also observed that although sulfur facilitates the formation of active sites of type $\mathrm{Fe}-\mathrm{N}_{x}$, this does not directly translate the catalysts with the highest $\mathrm{Fe}-\mathrm{N}_{x} \mathrm{SD}$ in the most active catalysts. This is explained considering the presence of other active sites (pyridinic and pyrrolic) important in the ORR and for the necessary presence of a hierarchical porosity that allows a more effective exposure of $\mathrm{Fe}-\mathrm{N}_{x}$ and to improve the TOF of active sites. In summary, in this set of catalysts, sulfur participates indirectly in activity enhancement modifying the textural properties and/or the formation of active sites, while a direct electronic effect was not straightforward.

\section{ASSOCIATED CONTENT}

\section{Supporting Information}

The Supporting Information is available free of charge at https://pubs.acs.org/doi/10.1021/acsami.1c09659.

TEM images, $S$ 2p XPS spectra, tables for Raman deconvolution parameters, element analysis by XPS of FeSMCx, electrochemical parameter from RRDE analysis, stripping data, and utilization factor (PDF)

\section{AUTHOR INFORMATION}

\section{Corresponding Author}

Christian Durante - Department of Chemical Sciences, University of Padova, 35131 Padova, Italy; 으이.org/ 0000-0002-8764-1219; Email: christian.durante@unipd.it

\section{Authors}

Giorgia Daniel - Department of Chemical Sciences, University of Padova, 35131 Padova, Italy

Marco Mazzucato - Department of Chemical Sciences, University of Padova, 35131 Padova, Italy

Riccardo Brandiele - Department of Chemical Sciences, University of Padova, 35131 Padova, Italy

Laura De Lazzari - Department of Chemical Sciences, University of Padova, 35131 Padova, Italy

Denis Badocco - Department of Chemical Sciences, University of Padova, 35131 Padova, Italy

Paolo Pastore - Department of Chemical Sciences, University of Padova, 35131 Padova, Italy

Tomasz Kosmala - Department of Chemical Sciences, University of Padova, 35131 Padova, Italy; 이이.org/ 0000-0002-0026-8205

Gaetano Granozzi - Department of Chemical Sciences,

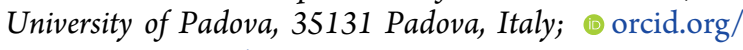
0000-0002-9509-6142

Complete contact information is available at:

https://pubs.acs.org/10.1021/acsami.1c09659

\section{Notes}

The authors declare no competing financial interest.

\section{ACKNOWLEDGMENTS}

The research leading to these results received funding from the Fuel Cells and Hydrogen 2 Joint Undertaking under grant agreement no. 779366, CRESCENDO. This Joint Undertaking received support from the European Union's Horizon 2020 
research and innovation program, Hydrogen Europe and Hydrogen Europe Research.

\section{REFERENCES}

(1) Ajanovic, A.; Haas, R. Prospects and Impediments for Hydrogen and Fuel Cell Vehicles in the Transport Sector. Int. J. Hydrogen Energy 2021, 46, 10049-10058.

(2) Edwards, R. L.; Font-Palma, C.; Howe, J. The Status of Hydrogen Technologies in the UK: A Multi-Disciplinary Review. Sustainable Energy Technol. Assess. 2021, 43, No. 100901.

(3) Kakoulaki, G.; Kougias, I.; Taylor, N.; Dolci, F.; Moya, J.; JägerWaldau, A. Green Hydrogen in Europe-A Regional Assessment: Substituting Existing Production with Electrolysis Powered by Renewables. Energy Convers. Manage. 2021, 228, No. 113649.

(4) Noussan, M.; Raimondi, P. P.; Scita, R.; Hafner, M. The Role of Green and Blue Hydrogen in the Energy Transition-A Technological and Geopolitical Perspective. Sustainability 2021, 13, No. 298.

(5) Kovač, A.; Paranos, M.; Marciuš, D. Hydrogen in Energy Transition: A Review. Int. J. Hydrogen Energy 2021, 46, 10016-10035.

(6) Davis, S. J.; Lewis, N. S.; Shaner, M.; Aggarwal, S.; Arent, D.; Azevedo, I. L.; Benson, S. M.; Bradley, T.; Brouwer, J.; Chiang, Y. M.; Clack, C. T. M.; Cohen, A.; Doig, S.; Edmonds, J.; Fennell, P.; Field, C. B.; Hannegan, B.; Hodge, B. M.; Hoffert, M. I.; Ingersoll, E.; Jaramillo, P.; Lackner, K. S.; Mach, K. J.; Mastrandrea, M.; Ogden, J.; Peterson, P. F.; Sanchez, D. L.; Sperling, D.; Stagner, J.; Trancik, J. E.; Yang, C. J.; Caldeira, K. Net-Zero Emissions Energy Systems. Science 2018, 360, No. eaas 9793.

(7) Brandiele, R.; Guadagnini, A.; Girardi, L.; Dražić, G.; Dalconi, M. C.; Rizzi, G. A.; Amendola, V.; Durante, C. Climbing the Oxygen Reduction Reaction Volcano Plot with Laser Ablation Synthesis of $\mathrm{Pt}$ x Y Nanoalloys. Catal. Sci. Technol. 2020, 10, 4503-4508.

(8) Brandiele, R.; Zerbetto, M.; Dalconi, M. C.; Rizzi, G. A.; Isse, A. A.; Durante, C.; Gennaro, A. Mesoporous Carbon with Different Density of Thiophenic-Like Functional Groups and Their Effect on Oxygen Reduction. ChemSusChem 2019, 12, 4229-4239.

(9) Brandiele, R.; Amendola, V.; Guadagnini, A.; Rizzi, G. A.; Badocco, D.; Pastore, P.; Isse, A. A.; Durante, C.; Gennaro, A. Facile Synthesis of $\mathrm{Pd}_{3} \mathrm{Y}$ Alloy Nanoparticles for Electrocatalysis of the Oxygen Reduction Reaction. Electrochim. Acta 2019, 320, 134563134572.

(10) Daniel, G.; Foltran, E.; Brandiele, R.; Nodari, L.; Pilot, R.; Menna, E.; Rizzi, G. A.; Isse, A. A.; Durante, C.; Gennaro, A. Platinum-Free Electrocatalysts for Oxygen Reduction Reaction: $\mathrm{Fe}-\mathrm{N}_{x}$ Modified Mesoporous Carbon Prepared from Biosources. J. Power Sources 2018, 402, 434-446.

(11) Daniel, G.; Kosmala, T.; Dalconi, M. C.; Nodari, L.; Badocco, D.; Pastore, P.; Lorenzetti, A.; Granozzi, G.; Durante, C. Upcycling of Polyurethane into Iron-Nitrogen-Carbon Electrocatalysts Active for Oxygen Reduction Reaction. Electrochim. Acta 2020, 362, No. 137200

(12) Wang, L.; Wan, X.; Liu, S.; Xu, L.; Shui, J. Fe-N-C Catalysts for PEMFC: Progress towards the Commercial Application under DOE Reference. J. Energy Chem. 2019, 39, 77-87.

(13) Wang, X.; Li, Z.; Qu, Y.; Yuan, T.; Wang, W.; Wu, Y.; Li, Y. Review of Metal Catalysts for Oxygen Reduction Reaction: From Nanoscale Engineering to Atomic Design. Chem 2019, 5, 1486-1511.

(14) Asset, T.; Atanassov, P. Iron-Nitrogen-Carbon Catalysts for Proton Exchange Membrane Fuel Cells. Joule 2020, 4, 33-44.

(15) Facchin, A.; Zerbetto, M.; Gennaro, A.; Vittadini, A.; Forrer, D.; Durante, C. Oxygen Reduction Reaction at Single Site Catalysts: A Combined Electrochemical Scanning Tunnelling Microscope and DFT Investigation of Iron Octaethylporphyrin Chloride on HOPG. ChemElectroChem 2021, 8 (15), 2825-2835.

(16) Facchin, A.; Kosmala, T.; Gennaro, A.; Durante, C. Electrochemical Scanning Tunneling Microscopy Investigations of $\mathrm{FeN}_{4}$ Based Macrocyclic Molecules Adsorbed on $\mathrm{Au}(111)$ and Their Implications in the Oxygen Reduction Reaction. ChemElectroChem 2020, 7, 1431-1437.
(17) Zagal, J. H.; Specchia, S.; Atanassov, P. Mapping Transition Metal-MN $\mathrm{M}_{4}$ Macrocyclic Complex Catalysts Performance for the Critical Reactivity Descriptors. Curr. Opin. Electrochem. 2021, 27, No. 100683.

(18) Jiao, L.; Li, J.; Richard, L. L.; Sun, Q.; Stracensky, T.; Liu, E.; Sougrati, M. T.; Zhao, Z.; Yang, F.; Zhong, S.; Xu, H.; Mukerjee, S.; Huang, Y.; Cullen, D. A.; Park, J. H.; Ferrandon, M.; Myers, D. J.; Jaouen, F.; Jia, Q. Chemical Vapour Deposition of $\mathrm{Fe}-\mathrm{N}-\mathrm{C}$ Oxygen Reduction Catalysts with Full Utilization of Dense $\mathrm{Fe}-\mathrm{N}_{4}$ Sites. Nat. Mater. 2021, 1-7.

(19) Guo, J.; Yan, X.; Liu, Q.; Li, Q.; Xu, X.; Kang, L.; Cao, Z.; Chai, G.; Chen, J.; Wang, Y.; Yao, J. The Synthesis and Synergistic Catalysis of Iron Phthalocyanine and Its Graphene-Based Axial Complex for Enhanced Oxygen Reduction. Nano Energy 2018, 46, 347-355.

(20) Vezzù, K.; Bach Delpeuch, A.; Negro, E.; Polizzi, S.; Nawn, G.; Bertasi, F.; Pagot, G.; Artyushkova, K.; Atanassov, P.; Di Noto, V. FeCarbon Nitride "Core-Shell" Electrocatalysts for the Oxygen Reduction Reaction. Electrochim. Acta 2016, 222, 1778-1791.

(21) Wei, Q.; Zhang, G.; Yang, X.; Chenitz, R.; Banham, D.; Yang, L.; Ye, S.; Knights, S.; Sun, S. 3D Porous $\mathrm{Fe} / \mathrm{N} / \mathrm{C}$ Spherical Nanostructures As High-Performance Electrocatalysts for Oxygen Reduction in Both Alkaline and Acidic Media. ACS Appl. Mater. Interfaces 2017, 9, 36944-36954.

(22) Yang, D. S.; Bhattacharjya, D.; Song, M. Y.; Razmjooei, F.; Ko, J.; Yang, Q. H.; Yu, J. S. Nitrogen-Doped Ordered Mesoporous Carbon with Different Morphologies for the Oxygen Reduction Reaction: Effect of Iron Species and Synergy of Textural Properties. ChemCatChem 2015, 7, 2882-2890.

(23) Mazzucato, M.; Daniel, G.; Mehmood, A.; Kosmala, T.; Granozzi, G.; Kucernak, A.; Durante, C. Effects of the Induced Microand Meso-Porosity on the Single Site Density and Turn over Frequency of $\mathrm{Fe}-\mathrm{N}-\mathrm{C}$ Carbon Electrodes for the Oxygen Reduction Reaction. Appl. Catal., B 2021, 291, No. 120068.

(24) Daniel, G.; Kosmala, T.; Brombin, F.; Mazzucato, M.; Facchin, A.; Dalconi, M. C.; Badocco, D.; Pastore, P.; Granozzi, G.; Durante, C. Highly Graphitized $\mathrm{Fe}-\mathrm{N}-\mathrm{C}$ Electrocatalysts Prepared from Chitosan Hydrogel Frameworks. Catalysts 2021, 11, No. 390.

(25) Zhou, Y.; Chen, G.; Wang, Q.; Wang, D.; Tao, X.; Zhang, T.; Feng, X.; Müllen, K. Fe-N-C Electrocatalysts with Densely Accessible Fe-N 4 Sites for Efficient Oxygen Reduction Reaction. Adv. Funct. Mater. 2021, No. 2102420.

(26) Lee, S. H.; Kim, J.; Chung, D. Y.; Yoo, J. M.; Lee, H. S.; Kim, M. J.; Mun, B. S.; Kwon, S. G.; Sung, Y.-E.; Hyeon, T. Design Principle of $\mathrm{Fe}-\mathrm{N}-\mathrm{C}$ Electrocatalysts: How to Optimize Multimodal Porous Structures? J. Am. Chem. Soc. 2019, 141, 2035-2045.

(27) Han, J.; Bao, H.; Wang, J. Q.; Zheng, L.; Sun, S.; Wang, Z. L.; Sun, C. 3D N-Doped Ordered Mesoporous Carbon Supported SingleAtom $\mathrm{Fe}-\mathrm{N}-\mathrm{C}$ Catalysts with Superior Performance for Oxygen Reduction Reaction and Zinc-Air Battery. Appl. Catal., B 2021, 280, No. 119411.

(28) Perazzolo, V.; Durante, C.; Pilot, R.; Paduano, A.; Zheng, J.; Rizzi, G. A.; Martucci, A.; Granozzi, G.; Gennaro, A. Nitrogen and Sulfur Doped Mesoporous Carbon as Metal-Free Electrocatalysts for the in Situ Production of Hydrogen Peroxide. Carbon 2015, 95, 949963.

(29) Lu, Z.; Li, Z.; Huang, S.; Wang, J.; Qi, R.; Zhao, H.; Wang, Q.; Zhao, Y. Construction of 3D Carbon Network with N,B,F-Tridoping for Efficient Oxygen Reduction Reaction Electrocatalysis and High Performance Zinc Air Battery. Appl. Surf. Sci. 2020, 507, No. 145154.

(30) Guo, D.; Shibuya, R.; Akiba, C.; Saji, S.; Kondo, T.; Nakamura, J. Active Sites of Nitrogen-Doped Carbon Materials for Oxygen Reduction Reaction Clarified Using Model Catalysts. Science 2016, $351,361-365$.

(31) Singh, S. K.; Takeyasu, K.; Nakamura, J. Active Sites and Mechanism of Oxygen Reduction Reaction Electrocatalysis on Nitrogen-Doped Carbon Materials. Adv. Mater. 2019, 31, No. 1804297.

(32) Janßen, A.; Martinaiou, I.; Wagner, S.; Weidler, N.; Shahraei, A.; Kramm, U. I. Influence of Sulfur in the Precursor Mixture on the 
Structural Composition of $\mathrm{Fe}-\mathrm{N}-\mathrm{C}$ Catalysts. Hyperfine Interact. 2018, 239, No. 7.

(33) Kim, D.; Kim, G.; Oh, S.; Park, J.; Lee, S.; Yoon, S.; Lee, J.; Lee, W.; Jeon, T. Y.; Cho, E.; Sohn, K.; Yang, D. K.; Kim, J. Dual-Doping of Sulfur on Mesoporous Carbon as a Cathode for the Oxygen Reduction Reaction and Lithium-Sulfur Batteries. ACS Sustainable Chem. Eng. 2020, 8, 8537-8548.

(34) Paraknowitsch, J. P.; Thomas, A. Doping Carbons beyond Nitrogen: An Overview of Advanced Heteroatom Doped Carbons with Boron, Sulphur and Phosphorus for Energy Applications. Energy Environ. Sci. 2013, 6, 2839-2855.

(35) Chao, G.; Zhang, L.; Wang, D.; Chen, S.; Guo, H.; Xu, K.; Fan, W.; Liu, T. Activation of Graphitic Nitrogen Sites for Boosting Oxygen Reduction. Carbon 2020, 159, 611-616.

(36) Mun, Y.; Lee, S.; Kim, K.; Kim, S.; Lee, S.; Han, J. W.; Lee, J. Versatile Strategy for Tuning ORR Activity of a Single Fe- $\mathrm{N}_{4}$ Site by Controlling Electron-Withdrawing/Donating Properties of a Carbon Plane. J. Am. Chem. Soc. 2019, 141, 6254-6262.

(37) Shen, H.; Gracia-Espino, E.; Ma, J.; Zang, K.; Luo, J.; Wang, L.; Gao, S.; Mamat, X.; Hu, G.; Wagberg, T.; Guo, S. Synergistic Effects between Atomically Dispersed $\mathrm{Fe}-\mathrm{N}-\mathrm{C}$ and $\mathrm{C}-\mathrm{S}-\mathrm{C}$ for the Oxygen Reduction Reaction in Acidic Media. Angew. Chem., Int. Ed. 2017, 56, 13800-13804.

(38) Specchia, S.; Atanassov, P.; Zagal, J. H. Mapping Transition Metal-Nitrogen-Carbon Catalysts Performance on the Critical Descriptors Diagram. Curr. Opin. Electrochem. 2021, 27, No. 100687.

(39) Perazzolo, V.; Brandiele, R.; Durante, C.; Zerbetto, M.; Causin, V.; Rizzi, G. A.; Cerri, I.; Granozzi, G.; Gennaro, A. Density Functional Theory (DFT) and Experimental Evidences of MetalSupport Interaction in Platinum Nanoparticles Supported on Nitrogen- and Sulfur-Doped Mesoporous Carbons: Synthesis, Activity, and Stability. ACS Catal. 2018, 8, 1122-1137.

(40) Brandiele, R.; Durante, C.; Grądzka, E.; Rizzi, G. A.; Zheng, J.; Badocco, D.; Centomo, P.; Pastore, P.; Granozzi, G.; Gennaro, A. One Step Forward to a Scalable Synthesis of Platinum-Yttrium Alloy Nanoparticles on Mesoporous Carbon for the Oxygen Reduction Reaction. J. Mater. Chem. A 2016, 4, 12232-12240.

(41) Malko, D.; Kucernak, A.; Lopes, T. In Situ Electrochemical Quantification of Active Sites in $\mathrm{Fe}-\mathrm{N} / \mathrm{C}$ Non-Precious Metal Catalysts. Nat. Commun. 2016, 7, No. 13285.

(42) Daniel, G.; Zhang, Y.; Lanzalaco, S.; Brombin, F.; Kosmala, T.; Granozzi, G.; Wang, A.; Brillas, E.; Sirés, I.; Durante, C. ChitosanDerived Nitrogen-Doped Carbon Electrocatalyst for a Sustainable Upgrade of Oxygen Reduction to Hydrogen Peroxide in UV-Assisted Electro-Fenton Water Treatment. ACS Sustainable Chem. Eng. 2020, $8,14425-14440$.

(43) Bergna, D.; Hu, T.; Prokkola, H.; Romar, H.; Lassi, U. Effect of Some Process Parameters on the Main Properties of Activated Carbon Produced from Peat in a Lab-Scale Process. Waste Biomass Valorization 2020, 11, 2837-2848.

(44) Ko, T. H.; Kuo, W. S.; Hu, C. H. Raman Spectroscopic Study of Effect of Steam and Carbon Dioxide Activation on Microstructure of Polyacrylonitrile-Based Activated Carbon Fabrics. J. Appl. Polym. Sci. 2001, 81, 1090-1099.

(45) Artyushkova, K.; Serov, A.; Rojas-Carbonell, S.; Atanassov, P. Chemistry of Multitudinous Active Sites for Oxygen Reduction Reaction in Transition Metal-Nitrogen-Carbon Electrocatalysts. J. Phys. Chem. C 2015, 119, 25917-25928.

(46) Thommes, M.; Kaneko, K.; Neimark, A. V.; Olivier, J. P.; Rodriguez-Reinoso, F.; Rouquerol, J.; Sing, K. S. W. Physisorption of Gases, with Special Reference to the Evaluation of Surface Area and Pore Size Distribution (IUPAC Technical Report). Pure Appl. Chem. 2015, 87, 1051-1069.

(47) Kwiatkowski, M.; Fierro, V.; Celzard, A. Confrontation of Various Adsorption Models for Assessing the Porous Structure of Activated Carbons. Adsorption 2019, 25, 1673-1682.

(48) Gor, G. Y.; Thommes, M.; Cychosz, K. A.; Neimark, A. V. Quenched Solid Density Functional Theory Method for Character- ization of Mesoporous Carbons by Nitrogen Adsorption. Carbon 2012, 50, 1583-1590.

(49) Puziy, A. M.; Poddubnaya, O. I.; Gawdzik, B.; Sobiesiak, M. Comparison of Heterogeneous Pore Models QSDFT and 2DNLDFT and Computer Programs ASiQwin and SAIEUS for Calculation of Pore Size Distribution. Adsorption 2016, 22, 459-464.

(50) Tang, X.; Jiang, Z.; Li, Z.; Gao, Z.; Bai, Y.; Zhao, S.; Feng, J. The Effect of the Variation in Material Composition on the Heterogeneous Pore Structure of High-Maturity Shale of the Silurian Longmaxi Formation in the Southeastern Sichuan Basin, China. J. Nat. Gas Sci. Eng. 2015, 23, 464-473.

(51) Rasmussen, C. J.; Vishnyakov, A.; Thommes, M.; Smarsly, B. M.; Kleitz, F.; Neimark, A. V. Cavitation in Metastable Liquid Nitrogen Confined to Nanoscale Pores. Langmuir 2010, 26, 1014710157.

(52) Sadezky, A.; Muckenhuber, H.; Grothe, H.; Niessner, R.; Pöschl, U. Raman Microspectroscopy of Soot and Related Carbonaceous Materials: Spectral Analysis and Structural Information. Carbon 2005, 43, 1731-1742.

(53) Guo, M.; Wang, L.; Gao, Y.; Li, G. Trace Sulfur Promoted Fe, N-Codoped Carbon Black as Electrocatalyst for Oxygen Reduction Reaction. Int. J. Hydrogen Energy 2019, 44, 3625-3635.

(54) Sparkes, R.; Hovius, N.; Galy, A.; Kumar, R. V.; Liu, J. T. Automated Analysis of Carbon in Powdered Geological and Environmental Samples by Raman Spectroscopy. Appl. Spectrosc. 2013, 67, 779-788.

(55) Luo, E.; Xiao, M.; Wang, Y.; Ge, J.; Liu, C.; Xing, W. Structural Advantage Induced by Sulfur to Boost the Catalytic Performance of FeNC Catalyst towards the Oxygen Reduction Reaction. ChemCatChem 2018, 10, 3653-3658.

(56) Perazzolo, V.; Grądzka, E.; Durante, C.; Pilot, R.; Vicentini, N.; Rizzi, G. A.; Granozzi, G.; Gennaro, A. Chemical and Electrochemical Stability of Nitrogen and Sulphur Doped Mesoporous Carbons. Electrochim. Acta 2016, 197, 251-262.

(57) Beyssac, O.; Goffé, B.; Petitet, J.-P.; Froigneux, E.; Moreau, M.; Rouzaud, J.-N. On the Characterization of Disordered and Heterogeneous Carbonaceous Materials by Raman Spectroscopy. Spectrochim. Acta, Part A 2003, 59, 2267-2276.

(58) Mosconi, D.; Blanco, M.; Gatti, T.; Calvillo, L.; Otyepka, M.; Bakandritsos, A.; Menna, E.; Agnoli, S.; Granozzi, G. Arene C e H Insertion Catalyzed by Ferrocene Covalently Heterogenized on Graphene Acid. Carbon 2019, 143, 318-328.

(59) Blanco, M.; Mosconi, D.; Otyepka, M.; Medved', M.; Bakandritsos, A.; Agnoli, S.; Granozzi, G. Combined High Degree of Carboxylation and Electronic Conduction in Graphene Acid Sets New Limits for Metal Free Catalysis in Alcohol Oxidation. Chem. Sci. 2019, 10, 9438-9445.

(60) Pylypenko, S.; Mukherjee, S.; Olson, T. S.; Atanassov, P. NonPlatinum Oxygen Reduction Electrocatalysts Based on Pyrolyzed Transition Metal Macrocycles. Electrochim. Acta 2008, 53, 78757883.

(61) Levi, G.; Senneca, O.; Causà, M.; Salatino, P.; Lacovig, P.; Lizzit, S. Probing the Chemical Nature of Surface Oxides during Coal Char Oxidation by High-Resolution XPS. Carbon 2015, 90, 181-196.

(62) Abdul Razzaq, A.; Yao, Y.; Shah, R.; Qi, P.; Miao, L.; Chen, M.; Zhao, X.; Peng, Y.; Deng, Z. High-Performance Lithium Sulfur Batteries Enabled by a Synergy between Sulfur and Carbon Nanotubes. Energy Storage Mater. 2019, 16, 194-202.

(63) Wang, Z.; Dong, Y.; Li, H.; Zhao, Z.; Bin Wu, H.; Hao, C.; Liu, S.; Qiu, J.; Lou, X. W. D. Enhancing Lithium-Sulphur Battery Performance by Strongly Binding the Discharge Products on AminoFunctionalized Reduced Graphene Oxide. Nat. Commun. 2014, 5, No. 3239.

(64) Tawil, N.; Sacher, E.; Boulais, E.; Mandeville, R.; Meunier, M. $\mathrm{X}$-Ray Photoelectron Spectroscopic and Transmission Electron Microscopic Characterizations of Bacteriophage-Nanoparticle Complexes for Pathogen Detection. J. Phys. Chem. C 2013, 117, 2065620665. 
(65) Liu, Z.; Wang, Y. Characterization of Triazinedithiolsilane Polymeric Nanofilm Fabricated by Galvanostatic Technique on Copper Surface. Int. J. Electrochem. Sci. 2016, 11, 1434-1455.

(66) Bag, S.; Mondal, B.; Das, A. K.; Raj, C. R. Nitrogen and Sulfur Dual-Doped Reduced Graphene Oxide: Synergistic Effect of Dopants towards Oxygen Reduction Reaction. Electrochim. Acta 2015, 163, 16-23.

(67) Primbs, M.; Sun, Y.; Roy, A.; Malko, D.; Mehmood, A.; Sougrati, M.-T.; Blanchard, P.-Y.; Granozzi, G.; Kosmala, T.; Daniel, G.; Atanassov, P.; Sharman, J.; Durante, C.; Kucernak, A.; Jones, D.; Jaouen, F.; Strasser, P. Establishing Reactivity Descriptors for Platinum Group Metal (PGM)-Free $\mathrm{Fe}-\mathrm{N}-\mathrm{C}$ Catalysts for PEM Fuel Cells. Energy Environ. Sci. 2020, 13, 2480-2500.

(68) Hu, K.; Tao, L.; Liu, D.; Huo, J.; Wang, S. Sulfur-Doped Fe/N/ C Nanosheets as Highly Efficient Electrocatalysts for Oxygen Reduction Reaction. ACS Appl. Mater. Interfaces 2016, 8, 1937919385.

(69) Yang, Z.; Yao, Z.; Li, G.; Fang, G.; Nie, H.; Liu, Z.; Zhou, X.; Chen, X.; Huang, S. Sulfur-Doped Graphene as an Efficient MetalFree Cathode Catalyst for Oxygen Reduction. ACS Nano 2012, 6, 205-211.

(70) Villemson, K. M.; Kaare, K.; Raudsepp, R.; Käämbre, T.; Šmits, K.; Wang, P.; Kuzmin, A. V.; Sutka, A.; Shainyan, B. A.; Kruusenberg, I. Identification of Active Sites for Oxygen Reduction Reaction on Nitrogen- and Sulfur-Codoped Carbon Catalysts. J. Phys. Chem. C 2019, 123, 16065-16074.

(71) Shao, C.; Wu, L.; Zhang, H.; Jiang, Q.; Xu, X.; Wang, Y.; Zhuang, S.; Chu, H.; Sun, L.; Ye, J.; Li, B.; Wang, X. A Versatile Approach to Boost Oxygen Reduction of $\mathrm{Fe}-\mathrm{N}_{4}$ Sites by Controllably Incorporating Sulfur Functionality. Adv. Funct. Mater. 2021, No. 2100833.

(72) Ni, B.; Chen, R.; Wu, L.; Xu, X.; Shi, C.; Sun, P.; Chen, T. Optimized Enhancement Effect of Sulfur in $\mathrm{Fe}-\mathrm{N}-\mathrm{S}$ Codoped Carbon Nanosheets for Efficient Oxygen Reduction Reaction. ACS Appl. Mater. Interfaces 2020, 12, 23995-24006.

(73) Jaouen, F.; Lefêvre, M.; Dodelet, J.-P.; Cai, M. Heat-Treated $\mathrm{Fe} / \mathrm{N} / \mathrm{C}$ Catalysts for O 2 Electroreduction: Are Active Sites Hosted in Micropores? J. Phys. Chem. B 2006, 110, 5553-5558.

(74) Kozhushner, A.; Zion, N.; Elbaz, L. Methods for Assessment and Measurement of the Active Site Density in Platinum Group Metal-Free Oxygen Reduction Reaction Catalysts. Curr. Opin. Electrochem. 2021, 25, No. 100620.

(75) Malko, D.; Kucernak, A.; Lopes, T. Performance of Fe-N/C Oxygen Reduction Electrocatalysts toward $\mathrm{NO}_{2}^{-}, \mathrm{NO}$, and $\mathrm{NH}_{2} \mathrm{OH}$ Electroreduction: From Fundamental Insights into the Active Center to a New Method for Environmental Nitrite Destruction. J. Am. Chem. Soc. 2016, 138, 16056-16068. 